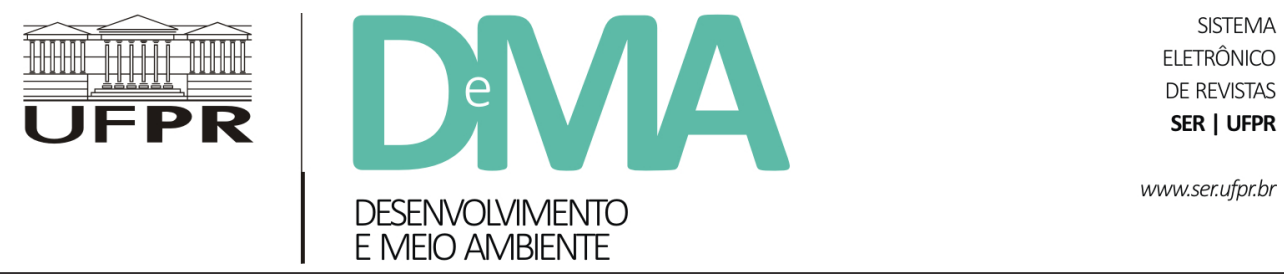

\title{
Do Protocolo Kyoto ao Acordo de Paris: uma análise das mudanças no regime climático global a partir do estudo da evolução de perfis de emissões de gases de efeito estufa
}

\section{From Kyoto Protocol to Paris Agreement: An Analysis of Global Climate Regime Changes Based on a Study of the Evolution of Green Gases Emissions Profiles}

\author{
Maria Cristina Oliveira SOUZA ${ }^{1 *}$, Rosana Icassatti CORAZZA ${ }^{1}$ \\ ${ }^{1}$ Departamento de Política Científica e Tecnológica (DPCT), Instituto de Geociências (IG), Universidade Estadual de Campinas (UNICAMP), \\ Campinas, SP, Brasil. \\ *E-mail de contato: mcris.ssouza@gmail.com
}

Artigo recebido em 20 de março de 2017, versão final aceita em 2 de novembro de 2017.

\begin{tabular}{|c|c|}
\hline & $\begin{array}{l}\text { O artigo recorre à noção de regime climático, aportado pela literatura de Relações Internacionais e por } \\
\text { abordagens interdisciplinares sobre mudanças climáticas, para a compreensão da normatização global do } \\
\text { problema das mudanças climáticas. Empregam-se, também, dados quantitativos e informações qualitativas } \\
\text { sobre emissões de gases de efeito estufa, afeitas aos domínios das Ciências do Clima e da Economia das } \\
\text { Mudanças Climáticas, a fim de apresentar e discutir mudanças recentes nos perfis de emissão de países } \\
\text { selecionados envolvidos na governança global do clima. Em consonância com essas mudanças, o regime } \\
\text { climático também tem se transformado. Dentre essas mudanças, destaca-se a emergência da abordagem "de } \\
\text { baixo para cima", representada pelo Acordo de Paris, que coroou a } 21^{a} \text { Conferência das Partes da Convenção- } \\
\text { Quadro das Nações Unidas sobre Mudanças Climáticas no final de } 2015 \text {, como alternativa à abordagem } \\
\text { "de cima para baixo" que caracterizou as negociações sob a égide do Protocolo de Kyoto. A discussão foi } \\
\text { feita a partir da análise das mudanças dos perfis de emissões de gases de efeito estufa pelos países que } \\
\text { integravam a arquitetura original do Protocolo de Kyoto e de outros agrupamentos que tomam forma ao longo } \\
\text { das sucessivas rodadas de negociação, com destaque para o BASIC, grupo formado por Brasil, África do Sul, } \\
\text { Índia e China. Demonstra-se que as reconfigurações de interesses dão origem a novas coalizões e lideranças } \\
\text { nas negociações sobre o tema, ao mesmo tempo em que devem proporcionar o reforço de velhos conflitos e o } \\
\text { surgimento de novas tensões. Assim, a discussão proposta neste artigo oferece elementos para a compreensão } \\
\text { dos rumos das negociações climáticas internacionais, que têm levado a uma reconfiguração da arquitetura do } \\
\text { regime climático, com mudanças substantivas em termos de liderança, de coalizão de países e de atribuição } \\
\text { de responsabilidades. }\end{array}$ \\
\hline
\end{tabular}


Palavras-chave: mudanças climáticas; perfis nacionais de emissões; regime climático; BASIC.

ABSTRACT: This paper uses the notion of climate regime provided by the International Relations literature and by interdisciplinary approaches on climate change. Such notion is important to understand the global normalization of the problem of climate change. Quantitative and qualitative data on greenhouse gas emissions, provided by Climate Sciences and the Economics of Climate Change, are used in order to present and discuss recent changes in emissions profiles of selected countries involved in the global climate governance. In line with these changes, the climate regime has also been transformed. The mentioned changes include the emergence of a "bottom-up" approach, represented by the Paris Agreement, which crowned the 21st Conference of the Parties to the UN Framework Convention on Climate Change at the end of 2015. It is regarded as an alternative to "top-down" approach that characterized the negotiations under the aegis of the Kyoto Protocol. The discussion is based on the analysis of changes in profiles of greenhouse gas emissions by the countries that were part of the original architecture of the Kyoto Protocol, as well as other groupings that took shape during the successive rounds of negotiations, especially BASIC, a group formed by Brazil, South Africa, India and China. Recent interest configurations have been shown to give rise to new coalitions and leadership in negotiations on the issue, while reinforcing old conflicts and creating new tensions. Thus, the discussion proposed in this article should provide elements for understanding the directions of international climate negotiations that have led to a reconfiguration of the architecture of the climate regime, with substantive changes in terms of leadership, coalition of countries and attribution of responsibilities.

Keywords: climate change; national emissions profiles; climate regime; BASIC.

\section{Introdução}

As mudanças climáticas compõem uma parte das questões que colocam a humanidade diante das chamadas fronteiras planetárias (planetary boundaries), termo proposto por Rockström et al. (2009) para compreender a problemática ambiental contemporânea numa perspectiva sistêmica, no sentido das interações entre os sistemas naturais e antrópicos ${ }^{1}$.

As mudanças climáticas apresentam, como as demais fronteiras planetárias, características que tipificam a problemática ambiental contemporânea: são problemas sistêmicos e complexos, com causalidades que não podem ser admitidas como unidirecionais, apresentando ciclos de retroalimentação; suas fontes múltiplas e difusas tornam difícil a atribuição de responsabilidade (o que é fundamental à aplicação do princípio do poluidorpagador, que orienta grande parte das políticas ambientais); suas consequências são cumulativas e se desdobram para além das fronteiras nacionais. Além disso, há um sensível interregno temporal entre a instalação das causas e as observações dos efeitos, o que coloca a dimensão intertemporal como central na apreensão dos nexos causa-efeito - os quais são estabelecidos com base em um conhecimento científico de fenômenos que estão nas

\footnotetext{
${ }^{1}$ Os autores definiram nove fronteiras planetárias ou limites planetários como sendo "o espaço operacional seguro para a humanidade em relação ao sistema terrestre": 1) Mudanças climáticas; 2) Taxa de perda da integridade da biosfera (que causa extinção de espécies); 3 ) Ciclos biogeoquímicos do fósforo e do nitrogênio; 4) Esgotamento do ozônio atmosférico, 5) Acidificação dos oceanos; 6) Utilização da água doce; 7) Mudança no uso da terra; 8) Carga atmosférica de aerossóis; e 9) Poluição química (como nuclear, poluentes orgânicos e metais pesados). Quatro delas foram ultrapassadas: as mudanças climáticas; a taxa da perda de integridade da biosfera; as mudanças no uso da terra e a interferência do ciclo do nitrogênio. Segundo os autores, a interdependência entre essas fronteiras faz com que elas devam ser tomadas de forma sistêmica. Romper
} 
fronteiras entre os sistemas antrópicos e naturais, sujeitos a incertezas nem sempre redutíveis a riscos probabilísticos. Por fim, seus desdobramentos podem incorrer em irreversibilidade de danos tanto para os sistemas socioeconômicos quanto para os sistemas terrestres (Corazza \& Bonacelli, 2014).

Como "outras imperfeições de mercado", conforme a elas se reporta Stern (2009), pode-se falar em "bens públicos globais", na formulação sugerida por Kaul et al. (1999) e em "global commons", na referência de Feny et al. (1990) e de Ostrom et al. (1999).

A necessidade da ação transfronteiriça possibilita, no âmbito da literatura da Ciência Política e da Economia Política Internacional, a articulação da ação coletiva para além dos territórios dos Estados nacionais, tomando a forma de regimes internacionais. Estes são "instituições sociais que governam as ações daqueles interessados em atividades especificadas (ou em um conjunto de atividades estabelecidas)" (Young, 1982, p. 277). Constituem as estruturas dos sistemas de governança internacional que, em nossos dias, são concebidos e implementados para articular os esforços para a resolução de problemas globais (Young, 2011, p. 19853). São constituídos como sistema de regras ou normas, especificadas por meio de um tratado internacional estabelecido entre representantes dos Estados nacionais, com a finalidade de regular as ações dos atores envolvidos (Haggard \& Simmons, 1987; Viola, 2002).

A solução para o problema da distribuição de custos e benefícios, dentro dos regimes internacionais climáticos, tem passado, no processo organizado pelas Nações Unidas, pela incorporação de princípios como o Princípio de Responsabilidade Comum, porém Diferenciada (PRDC) e o Princípio das Responsabilidades Históricas (PRH). São princípios que estão em jogo dentro da reconfiguração de forças na transição para o novo regime climático pós-Kyoto (Viola, 2002; Gupta, 2012; Bernauer, 2013; Okereke \& Coventry, 2016).

O processo das Nações Unidas, fundado na natureza global das mudanças climáticas e calcado na compreensão de que sua solução demanda, necessariamente, medidas que devem ser tomadas conjuntamente pelos países, tomou uma forma institucional com a Convenção-Quadro das Nações Unidas para as Mudanças Climáticas (UNFCCC, na sigla em inglês para United Nations Framework Convention for Climate Change), proposta em 1992, por ocasião da Segunda Conferência das Nações Unidas sobre Desenvolvimento e Meio Ambiente, conhecida como Rio 92. (Viola 2002; Okereke \& Covenry, 2016).

Organizadas no âmbito da UNFCCC com o objetivo geral de combater as mudanças climáticas, as negociações se desdobram por meio de rodadas internacionais sucessivas, nas quais os Estados nacionais, chamados de "Partes", deveriam se comprometer com ações voltadas às finalidades de mitigação e de adaptação, além de negociar os meios tecnológicos e financeiros para seu alcance. Assim, delegados dos Estados nacionais reúnem-se periodicamente nas Conferências das

um dos sistemas naturais significa colocar em risco os demais. (Rockström et al., 2009, p.472). Em 2015, Steffen et al. (2015) apresentaram um aperfeiçoamento do conceito, desenvolvendo uma abordagem em dois níveis, na qual são identificadas duas fronteiras "core", em que buscam dar conta de heterogeneidades em níveis regionais, atualizando a quantificação da maioria das fronteiras identificadas e apresentando uma quantificação em nível regional para uma das duas fronteiras que não haviam sido quantificadas no trabalho de 2009. 
Partes (COPs), que ocorrem desde 1995 - a COP de Berlim. As questões que animam os debates têm relação com responder a questões tais como: definição de metas globais, o que fazer, como fazer, quem deve fazer, quando e com o recurso a quais meios (Bueno Rubial, 2016).

As negociações se intensificaram em especial a partir de $2007^{2}$, quando da consolidação do conhecimento científico sobre causas, efeitos e recomendações sobre o problema das mudanças climáticas, momento em que o IPCC (na sigla em inglês Intergovernmental Panel on Climate Change,) foi laureado com o Prêmio Nobel da Paz.

Este artigo é dedicado a apresentar e discutir aspectos críticos das negociações climáticas, apresentando tanto o debate pré-Kyoto, como as discussões pós-Kyoto, tendo em foco um rearranjo específico entre as Partes. Em particular, o foco é a perda do papel de muitos dos países que compunham originalmente o Anexo I do Protocolo de Kyoto e a emergência de um conjunto de países que se articulam, para fins de negociação na ocasião da COP 15, em Copenhague, em 2009, como BASIC: Brasil, África do Sul, Índia e China.

Neste sentido, com base em ponderações de autores bem posicionados na análise das negociações sobre as mudanças climáticas, é oferecida - neste artigo - uma contribuição para o entendimento dos rumos das negociações mais recentes sobre as mudanças climáticas (Gupta, 2012; Viola, 2009; Bueno Rubial, 2016; Amorim et al., 2016; Bodansky, 2016; Boucher et al.,
2016; Carraro, 2016; Dimitrov, 2016; Okereke \& Coventry, 2016; Viola \& Basso, 2016; Heal \& Kunreuther, 2017; Afionis, 2017).

Esta contribuição consiste em colocar em perspectiva as emissões e posições dos grupos de países relevantes para as negociações climáticas em dois momentos, ou seja, no período de vigência do Protocolo de Kyoto e no período pós-Kyoto, que tem como um marco o Acordo de Paris, em 2015. A caracterização dos perfis de emissão é realizada com recurso a dados sobre as emissões dos países e agrupamentos de países em questão, coletados a partir da fonte CAIT - a Climate Analysis Indicators Tool, disponibilizada pelo World Resources Institute, que constitui a principal e mais reputada base de dados sobre o assunto.

Nesta contribuição, ganha destaque o contraponto entre o panorama de forças que vigeu no contexto que originou a arquitetura do Protocolo de Kyoto (com as emissões correntes e acumuladas associadas aos países do chamado Anexo I) e o panorama recente, no qual se observa emergir novas metas de redução das emissões por outro conjunto de países - com destaque para o BASIC, com o apelo a nova forma de atribuição de responsabilidades para o alcance dessas metas (Afionis, 2017).

Neste novo panorama, emerge o Acordo de Paris, que é interpretado por alguns autores como uma abordagem bottom up para as negociações climáticas (Bueno Rubial, 2016; Carraro, 2016; Okereke \& Coventry, 2016; Afionis, 2017). Nessa

\footnotetext{
${ }^{2}$ O Relatório AR4, que antecedeu o AR5, foi publicado em 2007 e foi um dos principais documentos que confirmaram que as ações antrópicas afetam os aumentos das emissões de GEE e as suas concentrações na atmosfera, como também influencia nas mudanças climáticas do planeta. Além disso, o Relatório afirma que se os aumentos da temperatura global ultrapassarem de $1,5^{\circ} \mathrm{C}$ a $2,5^{\circ} \mathrm{C}$, o risco de extinção de espécies vegetais e animais aumentará aproximadamente de $20 \%$ a 30\%. (IPCC, 2007b, p.26, disponível em: https://www.ipcc.ch/pdf/reports-nonUN-translations/ portuguese/ar4-wg2-spm.pdf).
} 
abordagem, as Partes apresentam - por si próprias suas metas de redução de GEEs, num novo arranjo em que, além dos países originalmente agrupados no Anexo I, também os emergentes - como é o caso do Brasil -, devem assumir novas responsabilidades, consolidadas na forma das iNDCs (Intended Nationally Determined Contributions), apresentadas por ocasião da Conferência das Partes - COP 21, em Paris no final de 2015.

$\mathrm{O}$ artigo está organizado em quatro seções, além desta introdução. Na segunda seção é apresentado o regime climático de Kyoto, discutido à luz dos agrupamentos de países - e de suas respectivas emissões históricas - num contexto de negociações do qual emerge a configuração do chamado Anexo I. Na terceira seção, são apresentadas, cotejadas e discutidas, as emissões de GEEs referentes a novas configurações de países emergentes (BRICS e BASIC).

Cotejar esses dados, tanto do ponto de vista das métricas das emissões acumuladas, como das emissões correntes para esses blocos, oferece - segundo aqui se propõe - elementos para a composição de um panorama dos conflitos envolvidos nas negociações internacionais sobre as mudanças climáticas que se desdobram com o final do prazo de vigência do Protocolo de Kyoto. Neste ponto, são problematizadas dificuldades, conflitos e consequências para a mudança do regime climático. A quarta seção aporta uma discussão sobre conflitos e tensões, antigos e novos, que se apresentam a partir da nova configuração que emerge a partir da reconfiguração do regime climático. Finalmente, a quinta seção corresponde às considerações finais, na qual se recupera sinteticamente a discussão do artigo e se apresentam suas principais conclusões.

\section{O regime climático de 1990 a 2009: princípios e arquitetura do Protocolo de Kyoto diante do histórico de emissões}

A busca pela solução do problema das mudanças climáticas na forma de negociações internacionais é compreendida pela construção de acordos que devem ser assinados - um compromisso preliminar pelos delegados e/ou chefes de Estado por ocasião das Conferências das Partes. Se forem legalmente vinculantes, sua ratificação pelas casas legislativas, em nível nacional, significa sua transformação em Políticas Nacionais e leis correspondentes (Gupta, 2012; Bodansky, 2016).

Como acontece com os problemas ambientais globais contemporâneos, as mudanças climáticas decorrem de impactos em escala planetária de atividades que se espalham para além de fronteiras nacionais (Rockstrom et al., 2009). A escala planetária ou transfronteiriça das fontes e dos impactos, associada ao caráter intergeracional do problema, colocam-no na esfera de soluções que implicam decisões de ordem interestatal (Viola, 2002).

Kaul et al. (1999), na organização de um trabalho pioneiro para o Programa das Nações Unidas para o Desenvolvimento (PNUD), afirmaram que os problemas envolvidos nas mudanças climáticas estão associados à degradação de um bem público global: a atmosfera. Dentro da abordagem da Economia do Bem-Estar, entendese que os mercados são eficientes em prover bens privados. O mercado, todavia, se funda num "conjunto de bens que ele próprio não pode prover: direitos de propriedade, previsibilidade, segurança, nomenclatura e assim por diante" (Kaul et al., 
1999, pp. xix-xx). Esses bens são providos pela ação coletiva normatizada pelo Estado, por meio de mecanismos não mercantis ou por meio de alguma forma mercantil modificada.

Os bens públicos apresentam, tipicamente, duas características: a não-rivalidade e a nãoexclusividade. A não-rivalidade significa que seu consumo não reduz sua disponibilidade - em quantidade e qualidade - para o consumo de terceiros. A não-exclusividade tem a ver com controle de acesso e significa que nenhum agente pode ser excluído do usufruto ou dos benefícios desse bem, seja porque isto seria extremamente custoso ou, no limite, tecnicamente impossível. Nessa linha, as mudanças climáticas seriam chamadas de global public bads (Kaul et al., 1999).

Contribuições no âmbito da Ciência Política, na Economia Política Internacional e também de estudos interdisciplinares enfatizam que, de forma singular, o caráter rival pode caracterizar o acesso a esses bens; ou seja, seu uso por um conjunto de agentes pode afetar sua disponibilidade, seja em quantidade, seja em qualidade, para outros. Nesta medida, não se falará mais em "bens públicos globais", mas em "global commons". Feny et al. (1990) apontam, neste sentido, a depleção da camada de ozônio e a acumulação de GEE na atmosfera de "tragédia dos comuns globais". Ostrom et al. (1999, p. 281) identificam na biodiversidade, nas mudanças climáticas e em outros serviços ecossistêmicos, elementos pertinentes aos global commons. Sua proteção demandaria, de acordo com os autores, a atuação de instituições multinível: instituições atuantes nas escalas local, regional e global. No âmbito destas últimas, um papel relevante cabe aos acordos globais.
A construção desses acordos significa a elaboração de princípios, normas, regras e procedimentos para a tomada de decisões em torno das quais convergem as expectativas dos agentes negociadores. Em torno desta construção se articula o conceito de Regime Internacional, sobre o qual, longe de existir um consenso, reserva-se um debate na área da Economia Política das Relações Internacionais. Neste debate, são confrontadas perspectivas distintas e não raro conflituosas - não apenas sobre o conceito de regime, como também a compreensão sobre os fenômenos que podem originá-los. Tais perspectivas passando tanto por tensões políticas, geopolíticas, ideológicas, quanto por fatores vinculados às tradições de pensamento sobre as quais as abordagens se constroem (Haggard \& Simmons, 1987).

Não cabe, no âmbito deste artigo, discutir as diferentes abordagens sobre regime internacional. Faz-se, todavia, necessário mencionar a existência de algumas abordagens gerais sobre o conceito. Krasner (2012; [1982]) propõe três abordagens para o significado dos regimes:

"[A primeira delas, representada, por exemplo, por Young, 1982; 2011, vê] os regimes como uma característica disseminada por todo o sistema internacional. Nenhum padrão de comportamento pode sustentar-se por qualquer período de tempo sem gerar um regime compatível. Os regimes e os comportamentos são inexoravelmente imbricados. [A segunda, representada por] Susan Strange (1982) [considera] que regime é um conceito enganoso que obscurece as relações básicas entre economia e poder. Strange [...] elabora uma crítica estrutural convencional que rejeita qualquer papel significativo para princípios, normas, regras e procedimentos para a tomada de decisões. [Finalmente, a terceira abordagem, que inclui Keohane (1982)] pode 
ser classificada de "estruturalista modificada", [aceitando] os pressupostos básicos das abordagens estrutural-realistas, as quais pressupõem um sistema internacional funcionalmente simétrico de Estados maximizadores de poder agindo num ambiente anárquico" (Krasner, 2012, p. 93-93).

Sem prejuízo para a proposta de Krasner, e considerando que a perspectiva de Strange (1982) na realidade é uma crítica ao conceito de regimes internacionais, Viola (2002) prefere identificar "duas concepções gerais sobre os regimes internacionais: uma formal (sentido estrito) e outra substantivo (sentido amplo) [...]" e se ater ao que há de comum nas distintas visões:

"de acordo com ambas as concepções, tais regimes são um sistema de regras, explicitadas num tratado internacional pactuado entre governos, que regulam as ações dos diversos atores sobre o assunto" (Viola, 2002, p. $27-28)^{3}$.

O regime climático seria, assim, uma forma específica de regime internacional, voltada ao tema das mudanças climáticas, buscando sua normatização, regulamentação e controle em escala transnacional. Especificamente, seus objetivos mais gerais incluiriam o controle e a redução das emissões dos GEEs em escala global.
Bueno Rubial (2016) analisa os princípios e normas que caracterizaram o regime climático em dois períodos: entre 1990 e 2009, o Regime do Protocolo de Kyoto; e a partir de 2009, a emergência de um regime climático pós-Kyoto, que tem no Acordo de Paris um marco nas negociações climáticas recentes ${ }^{4}$.

Nesta seção, são empregados dados sobre os perfis de emissões dos agrupamentos dos países segundo a arquitetura do Protocolo de Kyoto, a fim de apresentar e discutir os princípios sob a égide dos quais vigeu o regime deste Protocolo. A análise é amparada em parte em contribuições de autores que se debruçaram sobre o tema (Viola, 2002; 2009; 2010; Viola \& Basso, 2016; Bueno Rubial, 2016).

A configuração inicial do Protocolo de Kyoto, expressa pela reunião dos principais países responsáveis historicamente pelas emissões acumuladas de gás carbônico, responde, portanto, exatamente à ideia de uma atribuição justa de responsabilidades pela mitigação dessas emissões.

Conforme é possível observar pela Tabela 1, abaixo, esses países do Anexo I puderam, em grande parte por meio dos modos de desenvolvimento intensivos na queima de combustíveis fósseis, angariar para si nada menos que $82,45 \%$ dos fluxos mundiais de riqueza expressos pelo PIB - em

\footnotetext{
${ }^{3}$ Apreciações circunstanciadas sobre a literatura e sobre o debate a respeito de regimes internacionais podem ser encontradas em Haggard \& Simmons (1987) e Krasner (2012).

${ }^{4} \mathrm{O}$ Protocolo de Kyoto e o Acordo de Paris pertencem às categorias de instrumentos que foram desenvolvidos dentro do sistema das Nações Unidas em matéria de direito internacional a fim de permitir que os Estados estabeleçam entre si direitos e obrigações. Um protocolo (protocol) é um documento assinado ao final de uma Convenção, estabelecendo as intenções acordadas entre os delegados das Partes; um acordo (agreement) é o instrumento que tem sido utilizado como documento para selar as decisões tomadas ao final de Conferências, como é o caso das Conferências das Partes dentro da UNFCCC. Ambos os termos são utilizados de forma mais ou menos livre e equivalente em negociações internacionais e de maneira menos formal do que a noção de tratado (treaty), cuja não observância deve ter consequências previstas no próprio tratado, como sansões comerciais e multas, por exemplo. Todos são termos que se referem a documentos que coroam decisões tomadas em negociações internacionais. As definições dos termos chave empregados nas coleções de tratados das Nações Unidas são encontradas em: https:// treaties.un.org/Pages/overview.aspx?path=overview/definition/page1_en.xml.
} 
comparação com os $17,55 \%$ que cabem a todos os países do resto do mundo, em 1990, ano-base com relação ao qual o Protocolo de Kyoto previa originalmente a necessidade de reduções das emissões globais.

Por sua vez, a contribuição dos países do Anexo I para as emissões acumuladas de $\mathrm{CO}_{2}$ na atmosfera no período de 1850 a 1990 foi de $80,94 \%$, contra $19,06 \%$ de todos os demais países. Além disso, a parcela da população mundial que se beneficiou dessa riqueza à custa das referidas emissões é de $21,93 \%$ da população mundial, sem contar com outras distorções distributivas desta "pegada carbônica" que poderiam ser ainda maiores se eventualmente se levasse em conta as desigualdades na distribuição dos benefícios do desenvolvimento dentro desses próprios países ditos desenvolvidos.

O crescimento econômico intensivo em combustíveis fósseis é o principal motor das emissões acumuladas. Os países componentes do Anexo I, como grande parte dos países da União
Europeia, os Estados Unidos, o Canadá, a Federação Russa e o Japão, ainda são os responsáveis pela maior parte dessas emissões, o que sugere um dever moral desses países nas ações de mitigação dessas emissões.

Dessa forma, embora o problema das mudanças climáticas seja de natureza global, a contribuição dos grupos de países não é igual. Assim, um dos princípios que fundamenta o Protocolo de Kyoto é o da Responsabilidade Comum, porém Diferenciada. Bueno Rubial (2016, p. 80) explica que:

\begin{abstract}
“o regime climático, seus propósitos e princípios, em particular o Princípio de Responsabilidade Comum, porém Diferenciada (PRCD) constitui um modo de interpretar o caminho para cumprir o propósito no qual os países desenvolvidos deveriam ter a liderança tanto em matéria de redução de emissões como de provisão de meios para que os países em desenvolvimento pudessem gerar suas próprias ações climáticas".
\end{abstract}

Sampaio, Wold \& Nardy (2003, p. 14-15) notam que o PRCD tem sua origem já nos princípios

TABELA 1 - Emissões de CO2, correntes e acumuladas, população e Produto Interno Bruto, por grupo de países, reunidos segundo a configuração inicial do Protocolo de Kyoto (1990).

Indicadores

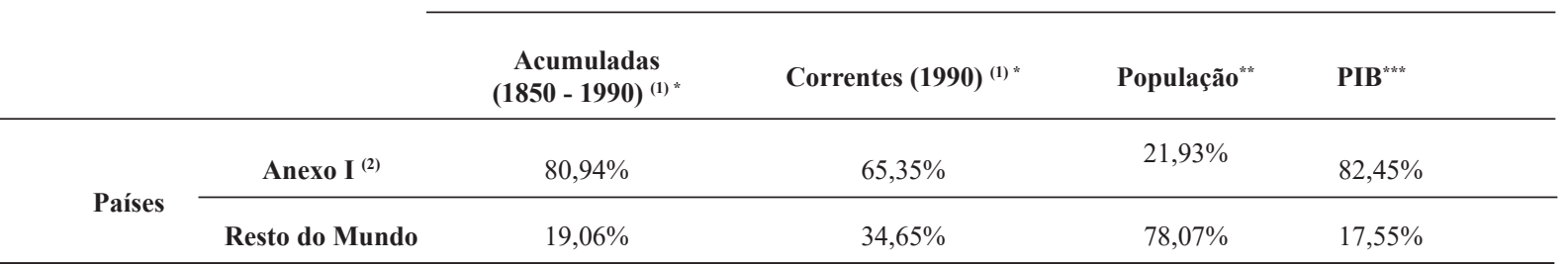

FONTES: Elaboração própria a partir da base de dados da * CAIT, ** United Nations - Department of Economic and Social Affairs e *** World Bank

NOTAS: (1) Emissões de $\mathrm{CO}_{2}$, excluindo AFOLU.

(2) Países do Anexo I, segundo a configuração original do Protocolo de Kyoto.

(3) Resto do Mundo: todos os países do mundo, excluindo-se os integrantes do Anexo I do Protocolo de Kyoto. 
de diversas negociações ambientais internacionais, por ocasião da Rio 92:

“Este princípio tem sua formulação associada aos esforços dos países em desenvolvimento para estabelecer critérios de compartilhamento da responsabilidade internacional pela solução de problemas ambientais globais que levem em consideração a realidade socioeconômica dos diferentes Estados. Historicamente, sua origem remonta às negociações travadas durante a Conferência da ONU sobre Meio Ambiente e Desenvolvimento de 1992, as quais resultaram em sua inscrição nos quatro documentos fundamentais originados do encontro: a Declaração do Rio, a Agenda 21, a ConvençãoQuadro sobre Mudanças Climáticas e a Convenção sobre Diversidade Biológica”.

Islândia
Luxemburgo
Nova Zelândia
Portugal
Irlanda
Noruega
Grécia
Finlândia
Suiça
Turquia
Dinamarca
Suécia
Áustria
Espanha
Países Baixos
Austrália
Bélgica
Itália
Canadá
Japão
França
Reino Unido
Alemanha
União Europeia (28)
Estados Unidos

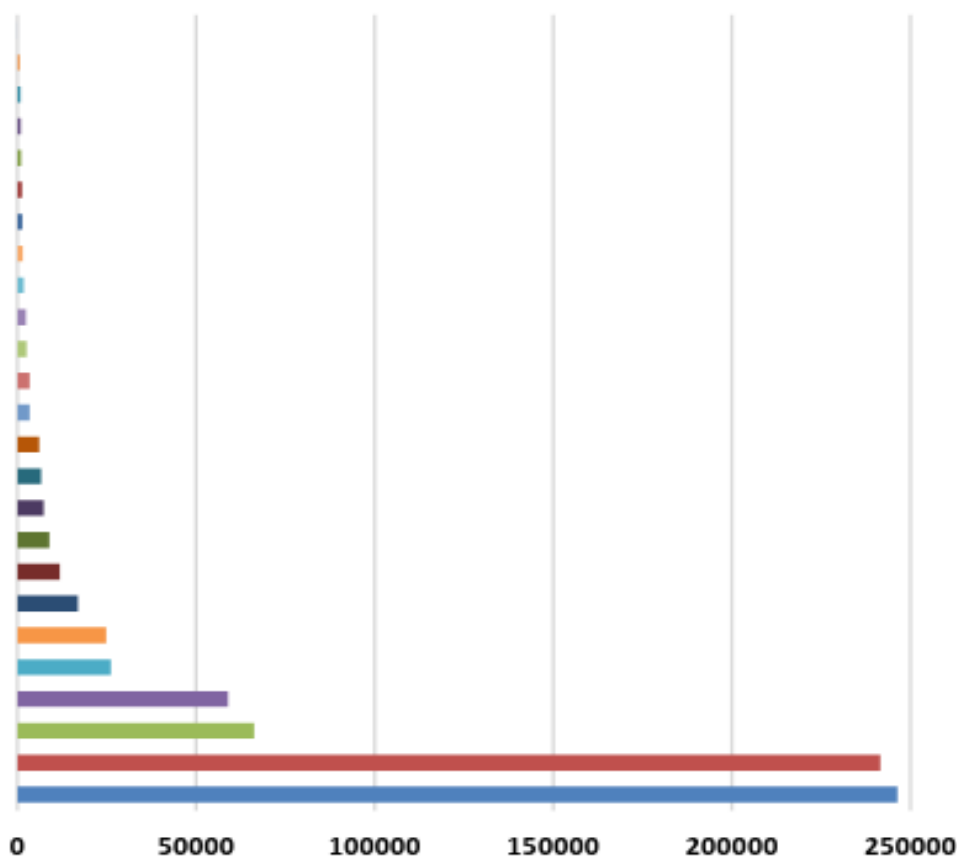

FIGURA 1 - Emissões Acumuladas Totais de $\mathrm{CO}_{2}\left(\mathrm{MtCO}_{2 \mathrm{e}}\right)$, excluindo AFOLU (1850 - 1990)

FONTE: Elaboração própria a partir da base de dados da CAIT Climate Data Explorer. 2016. Washington, DC: World Resources Institute. Disponível em: http://cait.wri.org/historical
Esse princípio é coerente com o que se observa em termos da contribuição dos diferentes países para as mudanças climáticas, conforme é possível comprovar por meio de diversas métricas.

Assim, é relevante que se note - ainda na Tabela 1 - que em 1990 os patamares das emissões muito superiores aos dos países do resto do mundo. Deste modo, observa-se quão significativa foi a escolha do ano de 1990 como ano-base com relação ao qual as reduções das emissões futuras deveriam ser computadas. E, também, quão significativa era a configuração do conjunto de países que compunham o Anexo I do Protocolo de Kyoto, ou seja, sua arquitetura. correntes dos países do Anexo I ainda se mostravam 
Graças a esforços realizados por diversas instituições ao redor do globo, como desenvolvimento de métodos para inventariar emissões correntes e contabilizar emissões acumuladas, é possível conhecer as emissões específicas de $\mathrm{CO}_{2}$ (excluindose AFOLU) - para um período bem mais extenso. A Figura 1 apresenta as emissões acumuladas totais dos países do Anexo 1, excluindo-se AFOLU, individualmente, com o destaque para o papel dos Estados Unidos e dos 28 países da União Europeia para o problema.

A fim de se aquilatar as emissões históricas de $\mathrm{CO}_{2}$, é possível recorrer a dados disponíveis na base de dados do World Resources Institute, a já mencionada CAIT, para o período que vai de 1850 a 1990. Emissões acumuladas historicamente neste período, mensuradas para o gás carbônico, não sendo incluídas as emissões associadas à agricultura, ao setor florestal e a outros usos da terra (AFOLU), é uma métrica para a contabilização das emissões associadas às mudanças climáticas que faz um sentido particular dentro do regime climático do Protocolo de Kyoto. Trata-se de uma abordagem para as negociações que leva em conta o problema da queima de combustíveis fósseis, em especial nos países de industrialização pioneira e avançada.

As emissões acumuladas são consideradas uma proxy da responsabilidade de cada país em relação às mudanças climáticas, uma vez descrevem o total de emissões históricas de cada um deles. Assim, trata-se de uma métrica utilizada justamente para compreender a extensão da responsabilidade histórica de cada país pelo problema das mudanças climáticas $^{5}$. São as emissões acumuladas, década após década, desde os princípios da Revolução Industrial na Inglaterra, mas que atingem um patamar sem precedentes a partir do segundo pósguerra - que conferem às mudanças climáticas seu caráter de problema ambiental intertemporal.

No regime climático do Protocolo de Kyoto, a responsabilidade por essas emissões acumuladas historicamente cabe ao conjunto de poluidores, ou seja, os países que integram o Anexo 1. A responsabilidade pela mitigação das emissões correntes, todavia, precisaria ser "distribuída" entre os países que estão em sua origem, pelo menos de acordo com o PRCD. O Protocolo de Kyoto utilizou, primeiramente, as emissões correntes para se basear nas reduções. Depois, alguns países como Brasil e China reivindicaram o cálculo com base na emissão histórica quando as suas emissões correntes começaram a aumentar.

Observa-se que:

\begin{abstract}
"Essa leitura foi enriquecida pelo Princípio das Responsabilidades Históricas, originalmente enunciado pelo Brasil no contexto das negociações do Protocolo de Kyoto, logo seguido pela China e pela Índia” (Bueno Rubial, 2016, p. 80).
\end{abstract}

Em outras palavras:

"Ele [o Princípio das Responsabilidades Históricas]
está baseado na história de cada país, relacionando
o desenvolvimento econômico com o uso de
combustível fóssil no passado, seja para promover
a Revolução Industrial, seja para mover motores a

\footnotetext{
${ }^{5}$ Deve-se notar que essa medida pode variar segundo a data de início escolhida e segundo a inclusão dos diversos tipos de gases e setores. Por exemplo, uma eventual exclusão das emissões associadas ao uso da terra, da agricultura e da atividade florestal pode minorar substantivamente as emissões de países como o Brasil e a Indonésia
} 
explosão, usados em transporte, ou para a geração de energia elétrica" (Ribeiro, 2002, p. 78).

A Figura 2, abaixo, mostra as emissões totais acumuladas entre 1850 e 1990 . Nota-se, então, que os principais emissores correspondem - neste período - aos Estados Unidos e à União Europeia, cujas contribuições chegam a $62,8 \%$ do total das emissões globais de gás carbônico $\left(\mathrm{CO}_{2}\right)$.

Como é possível perceber, o uso dessa métrica que contabiliza as emissões de $\mathrm{CO}_{2}$ (excluindo AFOLU) reforça a ideia de que, do ponto de vista das relações internacionais, os países que contribuíram de forma mais importante para as emissões globais tenham responsabilidade diferenciada para promover as mudanças no sentido da desejada busca pela baixa intensidade de carbono. Mais ainda, isso ser aplica seja do ponto de vista do desenvolvimento de tecnologias ou das inovações que propiciem a emergência ou a exploração de trajetórias tecnológicas (ou de novos paradigmas, como advogam alguns, de baixa emissão de GEE), seja na forma do financiamento de iniciativas que proporcionem essas alternativas, ao lado - ainda - da promoção de estilos de vida coerentes com esse fim. Esses indicadores justificam e reforçam, portanto, dois princípios de responsabilidade do regime de Kyoto: o PRCD e o Princípio das Respon-

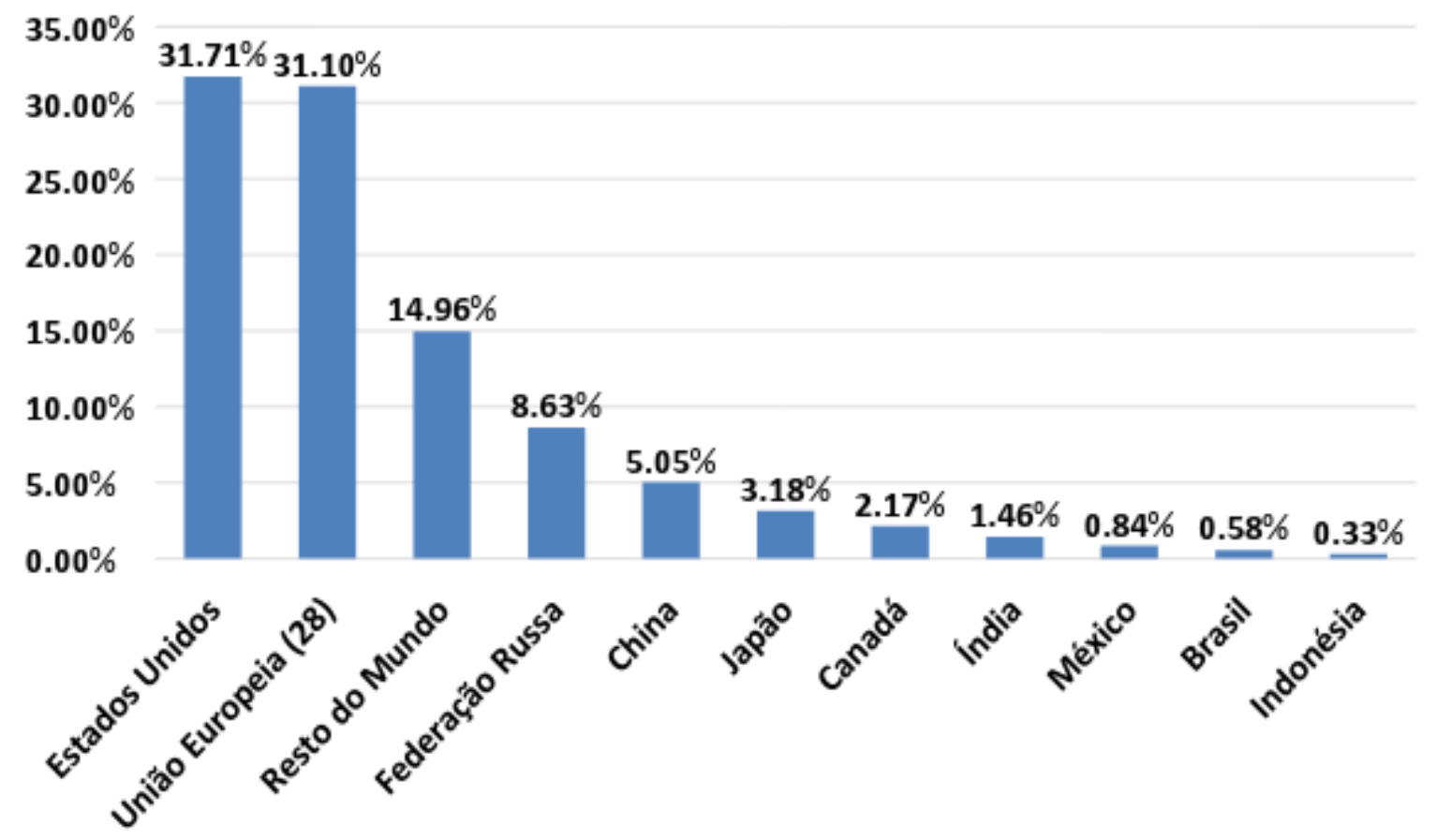

FIGURA 2 - Emissões Acumuladas de $\mathrm{CO}_{2}$ excluindo AFOLU (\% global) (1850-1990)

FONTE: Elaboração própria a partir da base de dados da CAIT Climate Data Explorer. 2016. Washington, DC: World Resources Institute. Disponível em: http://cait.wri.org/historical 
sabilidades Históricas.

É verdade, entretanto, que essa métrica não proporciona um quadro mais completo - e mais complexo - do problema. Os GEEs não se resumem ao $\mathrm{CO}_{2}$ e suas fontes, eles vão além da queima dos combustíveis fósseis. Observar outros indicadores e outras métricas ajuda a entender que o fenômeno das mudanças climáticas é influenciado pelas emissões de gases de efeito estufa - que vão além do gás carbônico.

Um exercício possível, por exemplo, é observar as emissões acumuladas incluindo o uso da terra e a atividade florestal para os principais dez países emissores para o período de 1990 a 2012 (correspondente ao último período para o qual a CAIT disponibiliza os valores), como proposto na Figura 3. Observa-se que quase metade das emissões acumuladas entre 1990 e 2012 (48,56\%) teve origem em apenas quatro países/regiões: os EUA, a China, a União Europeia e a Federação Russa.
Ou seja, já no período de vigência do regime climático do Protocolo de Kyoto, uma análise mais completa das contribuições dos diferentes países para o problema deixa evidente que compromissos de redução de emissões centrados nos principais emissores históricos (ou seja, os países do Anexo 1), deixariam de fora uma quantidade demasiadamente grande das emissões. Viola (2010) ressalta que no regime de Kyoto apenas $20 \%$ das emissões globais de GEEs estariam cobertas.

Duas condições, então, colocam-se enquanto avançam as negociações no regime de Kyoto: de um lado a evidência de que outros países (fora do Anexo 1) começaram a ter contribuições muito substanciais para as emissões globais. De outro, o fato de que enfrentar o problema das mudanças climáticas requer grandes esforços - e investimentos - em mitigação e em adaptação nas economias dos países em geral, e, sob esse regime climático, em especial naquelas dos principais responsáveis pelas emissões dos GEEs (Viola, 2010).

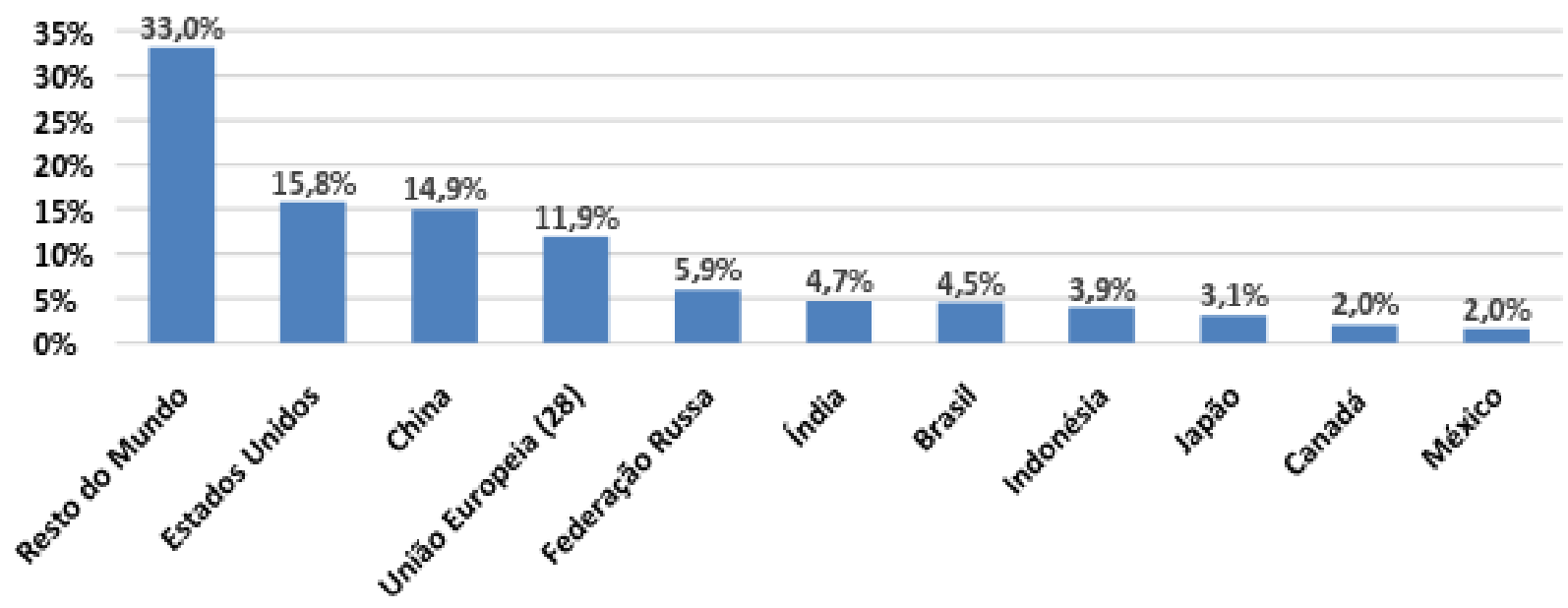

FIGURA 3 - Emissões Acumuladas de GEE (\%) incluindo AFOLU (1990 - 2012)

FONTE: Elaboração própria a partir da base de dados da CAIT Climate Data Explorer. 2016. Washington, DC: World Resources Institute. Disponível em: http://cait.wri.org 
Essas condições explicam, pelo menos em parte, a razão das dificuldades que emergiram no panorama das negociações internacionais no percurso de uma história de quase três décadas desde a criação do IPCC, em 1988. Algumas dessas dificuldades são encontradas em momentos críticos das negociações, como a situação particular da Rússia; a não ratificação do Protocolo de Kyoto pelos Estados Unidos; a saída do Canadá das negociações em 2011; e os conflitos envolvidos na necessidade de se estabelecer metas obrigatórias de redução de gases de efeito estufa pelos chamados países emergentes a partir do momento em que suas emissões passam a ser mais relevantes do que a de muitos dos países que pertenciam ao chamado Anexo I do Protocolo de Kyoto ${ }^{6}$.

Com relação à situação da Rússia, Bueno Rubial (2016) fala que, em troca de sua ratificação do Protocolo de Kyoto, a UE teve que negociar o reconhecimento deste país como uma economia de mercado, o que era necessário para destravar seu ingresso na Organização Mundial do Comércio.

No que diz respeito às dificuldades colocadas pelos Estados Unidos, a autora aponta que este país se ressentiu da ausência de outros países relevantes, como a China e a Índia, nos compromissos quantitativos de redução de emissões sob a égide do Protocolo de Kyoto. Viola (2002) nota que, embora tenha sido assinado por Bill Clinton em 1997, não foi imediatamente apresentado para ratificação pelo Senado norte-americano, a fim de dar tempo para tratativas internacionais, numa tentativa de ganhar adesão de países emergentes, tendo sido revogada em 2001 por George W. Bush. Sua eleição no ano anterior coroou uma plataforma que atribuía um papel importante dos combustíveis fósseis para o crescimento do país e que, do ponto de vista das negociações climáticas, reforçava a decisão política da não ratificação do Protocolo pelos Estados Unidos e que deixava claro que não aceitaria que toda a responsabilidade ficasse com os países desenvolvidos (Bueno Rubial, 2016; Viola, 2002).

Os mecanismos de mercado, que caracterizaram o Protocolo de Kyoto, como o mercado de carbono, não foram incentivos suficientes para a participação do país. Isso, embora tenha sido um negociador norte-americano, Tim Wirth (senador ambientalista do Colorado, então subsecretário de Estado para Assuntos Globais da Casa Branca), quem propôs em 1996, na COP 2 de Genebra - a ideia de cotas negociáveis de emissão de carbono (Viola, 2002).

Os EUA alegaram que a arquitetura do Protocolo de Kyoto, com o PRCD e a designação de um conjunto restrito de países com responsabilidades obrigatórias no Anexo I, constituiria um regime ineficiente e pouco robusto em comparação com seus equivalentes no Protocolo de Montreal, que entrou em vigor em 1989. Este último, voltado ao banimento das substâncias que comprometem a camada de ozônio, embora também reconhecesse uma diferenciação entre países desenvolvidos e em desenvolvimento, contemplava ações concretas para todas as partes, com um cronograma restritivo e não somente para um conjunto de Estados (Bueno Rubial, 2016, p. 80-81).

Em 2009, Barack Obama encaminhou o Protocolo para ser ratificado pelo Senado americano. Para os EUA há, ainda, mais um entrave: o acordo

${ }^{6} \mathrm{O}$ Anexo I reúne os países industrializados membros da Convenção do Clima da ONU que tinham metas obrigatórias de redução das emissões de GEE, aos níveis de 1990. 
ideal, assim como Kyoto, é "legalmente vinculante", ou seja, tem peso de lei e deve passar pelo legislativo dos países. Esta foi uma das razões, conforme afirma Ferreira (2011), pelas quais o Protocolo de Kyoto não teria sido aprovado no Senado do país.

No que tange ao posicionamento do Canadá, de acordo com Schmeller (2011), em dezembro de 2011, o Canadá se retirou do Protocolo de Kyoto, após o término da Conferência das Partes em Durban, sob a alegação de que se permanecesse no Protocolo o país estaria ameaçado a pagar multas no valor de 14 bilhões de dólares por não ter cumprido as metas de redução de GEEs. Ademais, o país depende da extração de minerais, dentre eles o petróleo, em especial de uma fonte não convencional (as areias betuminosas), cujas atividades de extração e refino emitem altas concentrações de dióxido de carbono e outras substâncias poluentes. Outra razão apontada pelo autor sobre a posição dos EUA, foi o fato de que os maiores emissores de GEEs, China e Estados Unidos, não aderiram ao Protocolo.

Essas dificuldades podem ser melhor compreendidas quando se considera a historicidade do fenômeno que está na origem das mudanças climáticas, qual seja o avanço da sociedade industrial alimentada energética e materialmente por insumos fósseis. $\mathrm{O}$ fato de que a maior parte dos estoques de GEEs foi acumulada a partir de fluxos que tiveram origem nos países que se industrializaram primeiro está na origem, como já observado anteriormente, da arquitetura do Protocolo de Kyoto, que colocou esses países no referido Anexo I, congregando aqueles que deveriam ter ações obrigatórias para a mitigação das mudanças climáticas.

Entretanto, o fenômeno histórico é dinâmico e, na medida em que outros países avançam em seus processos de industrialização, modernizam sua agricultura e promovem o avanço da exploração de seus territórios - incluindo a troca de florestas por pastagens ou por agricultura -, suas emissões correntes se tornam mais importantes. Ao longo de alguns anos, suas emissões acumuladas também avançam. A mudança nos perfis de emissão de países que estavam fora do Anexo 1 na arquitetura do regime climático de Kyoto se coaduna com novas articulações entre as Partes, colocando em questão, como será visto na próxima seção, sua eficácia, sua robustez e até mesmo seus princípios.

\section{Novos perfis de emissões e a emergência de um novo regime climático}

As razões para a ineficácia e para a falta de robustez do regime climático de Kyoto têm relação com o não engajamento de grandes emissores e com a não ratificação do Protocolo por essas partes, conforme mencionado na seção anterior. Neste sentido, os resultados observados neste trabalho corroboram a análise de outros autores (Gupta, 2012; Bernauer, 2013; Afionis, 2017).

Considerando que mudanças em princípios e normas significam mudanças nos próprios regimes internacionais, como propõe Krasner (2012), cabe examinar o caso das mudanças que se desdobram a partir de articulações de forças que se coadunam com as mudanças nos perfis das emissões de agrupamentos de países. Isso, para além do horizonte criado pelo Protocolo de Kyoto, o qual deveria expirar em 2012, mas que ganhou uma dilatação de prazo até 2015. É neste sentido que esta seção é articulada.

Os conflitos que surgem entre as Partes têm a ver com o ganho de importância das emissões 
correntes (totais ou absolutas) e acumuladas recentes de alguns países que ficaram fora do Anexo 1. Alguns aspectos das mudanças recentes nos perfis de emissão de gases de efeito estufa podem ser observados pela contribuição dos principais países para as emissões totais, incluindo AFOLU, na Figura 4, que mostra os dez maiores emissores, apresentados como nove países e mais uma região, a União Europeia, composta por 28 países $^{7}$, num total, portanto, de 37 países.

Os dados referem-se às emissões anuais totais, conhecidas também como emissões absolutas. As emissões absolutas correspondem às emissões correntes de cada um desses países, ou seja, a quantidade de GEEs emitida pelo país (medida em $\mathrm{MtCO}_{2} \mathrm{e}$ ) naquele ano. É, portanto, um conceito de fluxo. O conceito de emissões absolutas (ou anuais totais ou ainda correntes) é relevante porque seu cômputo ajuda - através do tempo - a explicar as concentrações atmosféricas de GEEs. Essas concentrações, também reportadas em $\mathrm{MtCO}_{2} \mathrm{e}$, constituem o estoque desses gases na atmosfera, cujo aumento ao longo do tempo é o responsável pelo fenômeno das mudanças climáticas induzidas por ações antrópicas (IPCC, 2007a).

Deste modo, se os grandes emissores de GEEs ao longo da história desempenharam um papel fundamental até agora para as mudanças climáticas, novos poluidores passam a contribuir, substantivamente, para a determinação do clima do planeta no futuro.

É possível constatar, analisando o gráfico, que trinta e sete países eram, em 2012, os responsáveis por $69,7 \%$ das emissões globais de GEEs. Esses países, neste mesmo ano, respondiam por $78,6 \%$ do PIB global e abrigavam pouco mais de $61,8 \%$ da população mundial. Já em 2012, a China aparecia como o principal emissor global de gases de efeito estufa. A Índia foi, naquele ano, o quarto emissor global - atrás da União Europeia (28 países). A lista segue, na seguinte ordem: Federação Russa, Indonésia e Brasil (que ficou, portanto, como o sétimo maior emissor).

Com o ganho de importância dessas emissões, o PRH que também reforçava o PRCD sob o regime de Kyoto, perde sua força. Ribeiro destaca que:

\begin{abstract}
"Países industrializados depois da Segunda Guerra Mundial [...] possuem uma responsabilidade menor que os países da Primeira Revolução Industrial, já que emitiram muito menos gases-estufa do que os demais industrializados. Não por acaso, [...] não estão entre os países do Anexo 1. A eles, porém, certamente caberá alguma restrição de emissão nos próximos anos. Isso decorre tanto do avanço da industrialização em seus territórios, que em geral alojam etapas da produção internacionalizada mais poluentes ou intensivas em consumo energético, quanto da pressão dos Estados Unidos, o principal opositor da exclusão do controle de emissões de gases-estufa por esse conjunto de países. Aliás, baseando-se nessa distinção justificam sua recusa em ratificar o Protocolo de Kyoto" (Ribeiro, 2002, p. 78).
\end{abstract}

Para que se evite um nível dramático de mudanças climáticas, seria necessário, de acordo com o AR5, que o nível de aquecimento global não ultrapassasse $2^{\circ} \mathrm{C}$. Neste sentido, é evidente

\footnotetext{
7 "União Europeia 28" corresponde à atual configuração de países que integram a UE em sua configuração econômica e política. Integram o grupo: Alemanha, Áustria, Bélgica, Bulgária, Chipre, Croácia, Dinamarca, Eslováquia, Eslovênia, Espanha, Estônia, Finlândia, França, Grécia, Hungria, Irlanda, Itália, Letônia, Lituânia, Luxemburgo, Malta, Países Baixos, Polônia, Portugal, Reino Unido, República Tcheca, Romênia e Suécia (para outras informações, $c f$. site oficial da União Europeia: https://europa.eu/european-union/about-eu/countries_pt).
} 
que todos os países identificados responsáveis pela maior parte das emissões precisariam urgentemente reduzi-las.

As dificuldades já mencionadas - a oposição dos Estados Unidos, a retirada do Canadá e outras posições reticentes de países integrantes do Anexo I - constituem resistências a esses princípios, que regeram as negociações internacionais sobre as mudanças climáticas no período de vigência do Protocolo de Kyoto.

Analisando as mudanças em curso ao longo das negociações climáticas recentes, Viola (2002) salienta que essas dificuldades devem ser compreendidas, também, como uma disputa pela liderança no regime climático. O papel da liderança é elucidado pelo autor, que destaca sua necessidade

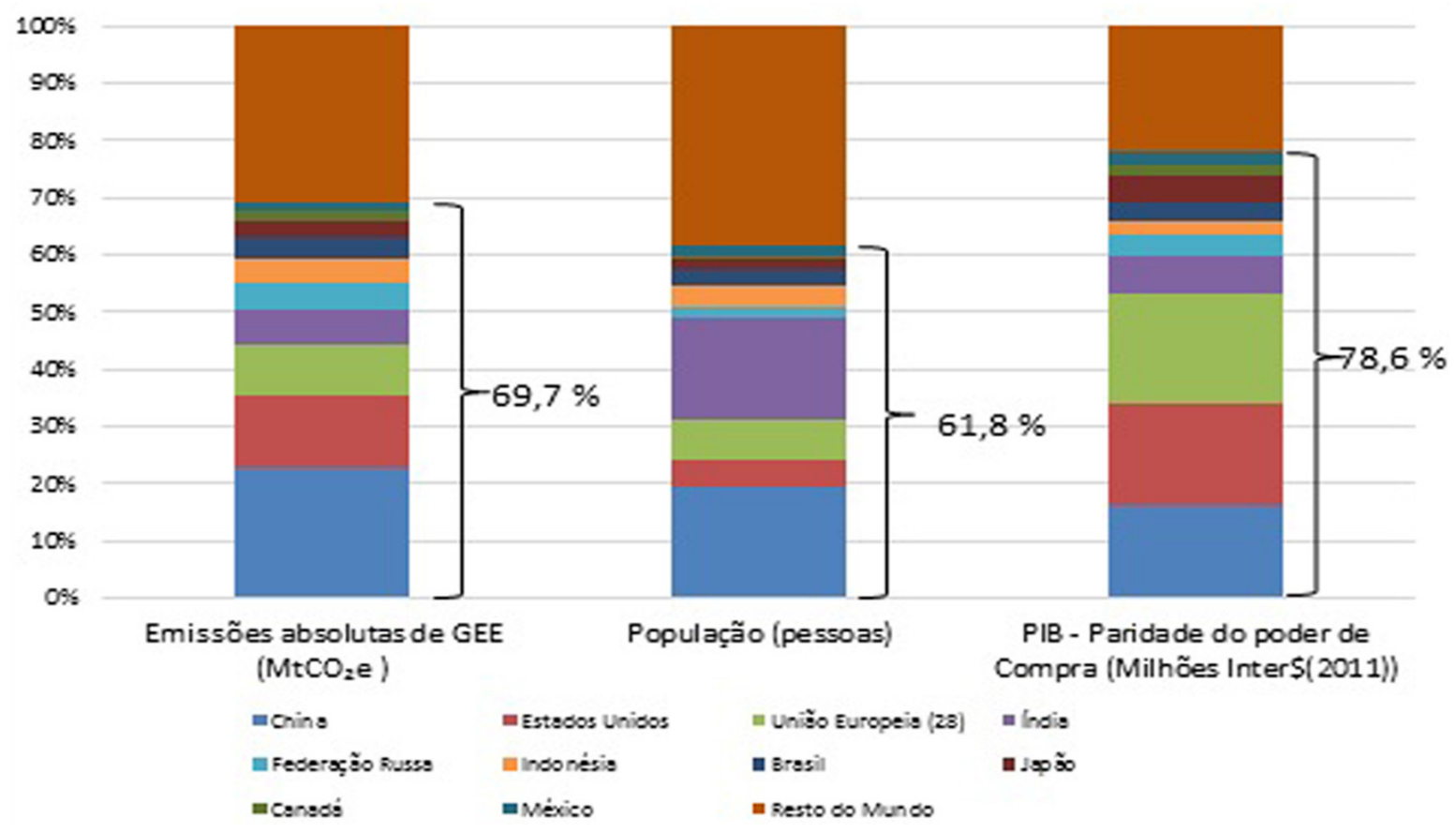

FIGURA 4 - Emissões anuais de GEE, incluindo AFOLU* (2012).

*AFOLU - Agriculture, Forestry and Other Land Use

(Agricultura, Setor Florestal e Outros Usos da Terra) ${ }^{8}$

FONTE: Elaboração própria a partir da base de dados da CAIT - Climate Data Explorer. 2016. Washington, DC: World Resources Institute. Disponível em: http://cait.wri.org/historical

NOTA: os números em destaque correspondem aos valores acumulados.

${ }^{8}$ Agricultura, Floresta e Outros Usos da Terra (AFOLU) representam o conjunto de "setores" que responde por cerca de um quarto das emissões antrópicas líquidas de GEE, sendo que as principais causas na origem dessas emissões são: i) o desmatamento; ii) as emissões agrícolas de manejo do solo e de nutrientes; e iii) a pecuária (IPCC, 2014a). 
no âmbito do regime de mudança climática no sentido de impulsionar o processo de negociações e de sustentar o regime (Viola, 2002, p. 30).

Ora, se a existência e a estabilidade de um regime internacional são resultados da manifestação de um Estado ou de uma coalizão de forças hegemônicas que conferem ao regime suas características de robustez e de eficácia, como propõe Krasner (2012), o engajamento de diferentes países no regime internacional envolve - necessariamente - algum grau de disputa pela liderança. No caso do regime climático do Protocolo de Kyoto, observam-se várias coalizões de interesse ao longo dos processos de negociação, ensejando clivagens e alinhamentos, inclusive a disputa pela liderança nos rumos das negociações (Viola, 2002).

Isso aconteceu com a União Europeia, de acordo com Bueno Rubial (2016, p. 81), enquanto vigeu o Protocolo de Kyoto. A EU exerceu um papel de liderança em sucessivas Convenções das Partes. Essa estabilidade do regime climático do Protocolo de Kyoto começou a se fragilizar, ainda de acordo com a autora, quando os Estados Unidos se mostraram interessados, sob a presidência de Obama, a participar ativamente das mudanças das regras e a uma reinterpretação dos princípios (PRCD e PRH) desse regime.

Em 2009, quando da COP 15, de Copenhague, um novo conjunto de forças começa a se aglutinar, conforme observa Viola (2010). Diante da discussão sobre ampliação das responsabilidades dos países emergentes, o BASIC tomou forma: Brasil, África do Sul, Índia e China, países que apresentaram taxas de crescimento recentes importantes (assim como a Federação Russa que, juntamente com os anteriores compõe o BRICS - sigla sugerida por Jim O'Neill, economista do banco Goldman Sachs em 2001).

Desta forma, a onda de crescimento econômico,

TABELA2 - Emissões de CO2, correntes e acumuladas, população e Produto Interno Bruto, por grupo de países, numa configuração "pós-Kyoto"

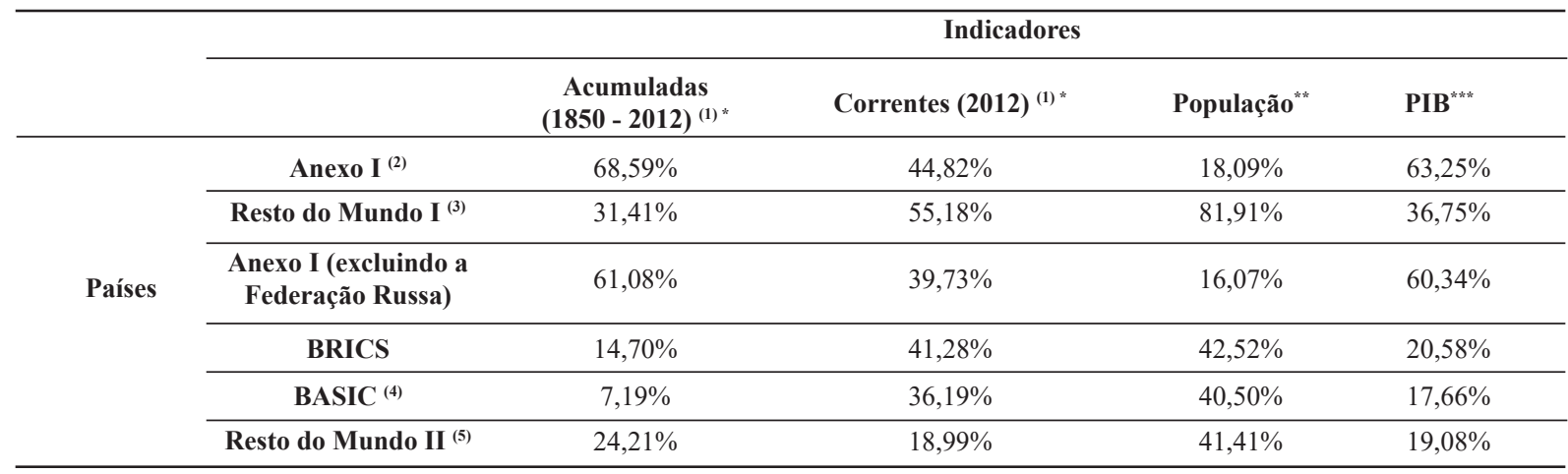

FONTES: Elaboração própria a partir da base de dados da * CAIT, ${ }^{* *}$ United Nations - Department of Economic and Social Affairs e ${ }^{* * * *}$ World Bank NOTAS: ${ }^{(1)}$ Emissões de $\mathrm{CO}_{2}$, excluindo AFOLU.

(2) Países do Anexo I, segundo a configuração original do Protocolo de Kyoto.

(3) Resto do Mundo I: todos os países do mundo, excluindo-se os do Protocolo de Kyoto.

(4) BASIC - Brasil, Índia, China e África do Sul

(5) Resto do Mundo II = Total de Países - [(ANEXO I - Federação Russa $)+$ BRICS $]$ 
que atingiu uma parte dos países que integravam o que foi chamado na tabela anterior de "Resto do Mundo", levou também a uma mudança da configuração dos países em termos de suas contribuições para as emissões globais, como se evidencia na Tabela 2 .

Observando as emissões do BRICS, nota-se que, no ano de 2012 - o mais recente para o qual as informações estão disponíveis -, esse conjunto respondeu por $41,28 \%$ das emissões correntes, embora por somente $14,7 \%$ das acumuladas.

As contribuições diferenciadas dos blocos de países para as emissões correntes e acumuladas evidenciam a crescente participação dos também chamados países emergentes para os fluxos correntes de emissões de GEE em geral, e de $\mathrm{CO}_{2}$ em particular. Essa mudança no perfil das emissões constitui um forte argumento nas negociações internacionais para que esses países assumam metas obrigatórias de redução dessas emissões.

Essa reorganização de países em blocos também significou a aproximação, ou, como sugere Viola (2010), uma nova coalizão de forças que produziu o Acordo de Copenhague que, conforme aponta o autor:

“[...] declara que é necessário evitar o aumento de $2^{\circ} \mathrm{C}$ da temperatura média da Terra e deixa o anexo final em branco para que os países definissem até o fim de janeiro de 2010 quais as metas de mitigação a que se comprometeriam" (Viola, 2010, p. 19).

Viola (2010) salienta que, enquanto o regime de Kyoto cobria somente $20 \%$ das emissões globais de GEEs, no Acordo de Copenhague essa cobertura chegava a $80 \%$, fundamentalmente em razão de um maior número de países apoiadores, incluindo EUA,
UE, Japão, Canadá, Austrália, Coreia do Sul, China, Índia, Brasil, África do Sul e Indonésia. Embora não tendo sido legalmente vinculante, veio a se tornar a base para o novo acordo global, estabelecido cinco anos mais tarde, em Paris.

Este foi o momento, 2009, e Copenhague, o lugar, que marcaram o início da mudança na arquitetura do que veio a ser um novo acordo climático pós-Kyoto e no regime climático. No novo regime, inclusive, é estabelecida uma nova relação de liderança:

\begin{abstract}
"De 1992 a 2009 a liderança europeia plasmou sua abordagem "de cima para baixo" com compromissos de mitigação estabelecidos pelo regime [climático] para os Estados concretizados no Protocolo de Kyoto para os países desenvolvidos. O compromisso internacionalmente assumido permitiu à União Europeia distribuir o peso de sua autoproclamada liderança internacional entre seus Estados - 'Partes'por meio de um sistema solidário de redução de emissões, com um papel relevante para o mercado e movido por alguns atores que tiveram papel prioritário como a Alemanha e a Grã-Bretanha" (Bueno Rubial, 2016, p. 81).
\end{abstract}

A desestabilização do regime de Kyoto em 2009 se deu pela determinação dos EUA em desempenhar um papel em sua discussão, questionando a interpretação europeia do regime e apontando para o estabelecimento de metas determinadas voluntariamente pelas Partes - as NDCs. Essa nova abordagem para a ação climática foi consolidada no Acordo de Paris (Afionis, 2017).

Para chegar ao documento do novo acordo, as Partes tiveram cerca de dois anos para decidir e apresentar suas NDCs, de modo que, ao longo do ano de 2015, a maioria das partes já havia submetido suas NDCs, que foram discutidas na 
$21^{\text {a }}$ Conferência das Partes (COP-21) da UNFCCC, ocorrida em Paris entre 30 de novembro e 12 de dezembro de $2015^{9}$.

O documento final que sela as negociações da COP21 foi chamado de Acordo de Paris (Paris Agreement), cujas determinações incluem:

- "Deter o aumento da temperatura global média do planeta abaixo de $2^{\circ} \mathrm{C}$ acima dos níveis préindustriais e empenhar esforços para limitar o aumento da temperatura a $1,5^{\circ} \mathrm{C}$ acima dos níveis pré-industriais, reconhecendo que isso reduziria significativamente os riscos e impactos da mudança climática;

- “Aumentar a habilidade para adaptação aos impactos adversos das mudanças climáticas e estimular a resiliência climática e o desenvolvimento com baixas emissões de GEEs, de uma maneira que não ameace a produção de alimentos;

- "Tornar os fluxos monetários consistentes com um caminho direcionado à redução das emissões de GEEs e ao desenvolvimento resiliente do ponto de vista climático" (Nações Unidas, 2015).

Bueno Rubial (2016) considera a abordagem um sucesso oriundo da aliança entre os Estados Unidos e o grupo BASIC, que se manteve desde Copenhague, em 2009, até Paris, em 2015.

O "sucesso" do novo regime, entretanto, está longe de ser um consenso entre analistas bem posicionados. Viola e Basso (2016), por exemplo, consideram que a coalizão dos países do BRIC se mostrou conservadora:
"The four countries have been conservative climate players. Their INDCs, for instance, should be a lot more ambitious in order to put the world on track of keeping close to $1.50 \mathrm{C}$ increase in global average temperature by 2100. They all should present more ambitious standings: China and India due to the current weight of their emissions in total global emissions; Russia due to its historical contribution to the increase of GHG concentration in the atmosphere; and Brazil due to its potential of further decreasing emissions and its alleged climate leadership. Their commitment to decarbonization should transcend the multilateral climate regime: further involvement with other multilateral fora, such as the International Renewable Energy Agency (IRENA) - whose creation was opposed by the four countries; yet later, China, India and Russia became members - and with decarbonization measures promoted by G20. These would be important signs of change in perspective regarding the issue" (Viola \& Basso, 2016, p. 18).

De uma posição privilegiada, como delegado de um governo de país desenvolvido na Conferência de Paris, Dimitrov (2016) observa cenas de negociação da diplomacia climática "behind closed doors". Dessas sessões, permitidas apenas a poucos negociadores governamentais - cerca de quatro por país, sem a participação da sociedade civil -, emergiram consensos sobre questões candentes do contencioso, incluindo o objetivo global de longo-prazo, o nível de ambição política do acordo, o caráter legalmente vinculante das ações de política em nível nacional, o financiamento e a evolução do regime ao longo do tempo. Também, evidentemente, os exatos termos empregados na redação do acordo. Chama a atenção uma das observações do autor sobre o acordo:

\footnotetext{
${ }^{9}$ Até agora (30 de outubro de 2017), 193 Partes apresentaram 166 contribuições (a União Europeia submeteu uma NDC representando seus 28 países-membros) ao Secretariado da UNFCCC. O Acordo de Paris estabeleceu, em seu $\S 13^{\circ}$, que as partes deveriam apresentar suas contribuições (INDCs) "well in advance of COP 22, in Marrakesh" (UNFCCC, 2016).
} 
"The PA [Paris Agreement] is weaker on the long-term global goal, adaptation policy, compensation for loss and damage, and technology transfer. Crucially, the PA locks specificity on the international division of labor for reducing emissions. The sharing of responsibility has been a central challenge in global negotiations" (Dimitrov, 2016, p. 8).

Apesar dessas fraquezas, o autor ainda considera que o Acordo de Paris pode ser considerado um sucesso político - "a diplomatic breakthrough" -, porque levou ao sucesso na formação de um novo regime climático internacional. Este resultado explica-se, ainda na visão do autor, por três fatores chave. $\mathrm{O}$ primeiro diz respeito ao acordo bilateral entre Estados Unidos e China, que teria provocado um salto no processo das Nações Unidas, evocando a noção de "club approach"10. $\mathrm{O}$ segundo fator seria a evidência da excelência das habilidades diplomáticas do país anfitrião, a França, que teria demonstrado "timing, pacing, sequencing and coordination of sessions, as well as the strategic rethoric [...] that [made French credited] for enabling success (Dimitrov, 2016, p. 9). E, finalmente, o terceiro fator chave teria sido uma mudança cognitiva geral entre as delegações negociadoras, que poderia ser apreciada pela boa aceitação e incorporação dos discursos do crescimento verde e das soluções win-win: o argumento de que as políticas climáticas podem trazer benefícios econômicos teria sido estrategicamente persuasiva, afetando as preferências de política e alterando os cálculos sobre custo-benefício, de modo a engajar as Partes em discursos favoráveis a transformar suas intenções declaradas em Paris em planos nacionais (idem).

A característica de bottom up é apontada pelo vice-presidente do Working Group III do IPCC como parte de um movimento em que:

\begin{abstract}
"International negotiations on climate change control are moving away from a global cooperative agreement (at least from the ambition to achieve it) to adopt a bottom-up framework composed of unilateral pledges of domestic measures and policies" (Carraro, 2016, p. 175).
\end{abstract}

A abordagem das NDCs, apresentadas voluntariamente pelas Partes, está no cerne do argumento segundo o qual o novo regime climático - que nasce a partir da COP 15 - pode ser caracterizado como bottom up, enquanto que o regime anterior, que vigeu entre 1992 e 2009, foi do tipo top down (Bueno Rubial, 2016; Carraro, 2016; Afionis, 2017; Heal \& Kunreuther, 2017).

As contribuições nacionais (NDCs) de cada país devem envolver a mitigação das mudanças climáticas, a promoção de medidas de adaptação e, ainda, a geração de oportunidades econômicas. Os analistas concordam que ainda não há como dizer em que medida poderá haver, contudo, a conciliação entre competição e cooperação entre os países na busca por um futuro possível sob as mudanças climáticas (Bodansky, 2016; Carraro, 2016; Dimitrov, 2016; Heal \& Kunreuther, 2017).

\footnotetext{
${ }^{10}$ A abordagem de clube, Club Approach, constitui uma contribuição recente baseada na Teoria dos Jogos para as negociações que envolvem muitos players com base na apresentação de intenções de mitigação de GEE. Num trabalho representativo, Heal \& Kunreuther (2017) sugerem centrar as negociações climáticas em pequenos grupos (clubs). Nessas negociações, os agentes podem ter seus comportamentos explicados a partir da expectativa de serem seguidos por outros negociadores. Um dos casos discutidos pelos autores é o do "US-China Joint Announcement on Climate Change", de 2014.
} 


\section{Velhos e novos conflitos no regime climático pós-Kyoto}

Sugere-se, aqui, a utilidade de três outras métricas para caracterizar as mudanças de regime climático e apontar alguns possíveis conflitos que tenderiam a se cristalizar, demandando eventualmente esforços de negociação e soluções.

Duas dessas métricas são propostas para avaliar e compreender as emissões dos diferentes países/regiões em termos de sua intensidade de emissões: uma delas com relação à intensidade de emissões do PIB (ton $\mathrm{CO}_{2}$ e/milhões de US\$ de PIB) e outra às emissões provenientes do consumo de energia fóssil. A terceira, relevante do ponto de vista histórico, tem a ver com a contribuição de cada país para o acúmulo (ou estoque) de GEEs na atmosfera. Vamos a elas.

Do ponto de vista do nível de emissões de GEEs por PIB, trata-se de uma métrica comum para a intensidade de emissões. É útil, particularmente, quando são examinadas as possibilidades de descarbonização de uma economia nacional ou de um sistema energético.

A figura 5, abaixo, apresenta a intensidade de emissões totais de GEEs e as emissões energéticas de GEEs do PIB para os dez principais países emissores. As médias mundiais para as emissões totais pelo PIB e médias mundiais de emissões provenientes do consumo de energias fósseis são, respectivamente, de 508,8 e de 375,2 toneladas de $\mathrm{GEE}\left(\mathrm{tCO}_{2} \mathrm{e}\right)$ por milhão de US \$ de PIB. Conforme

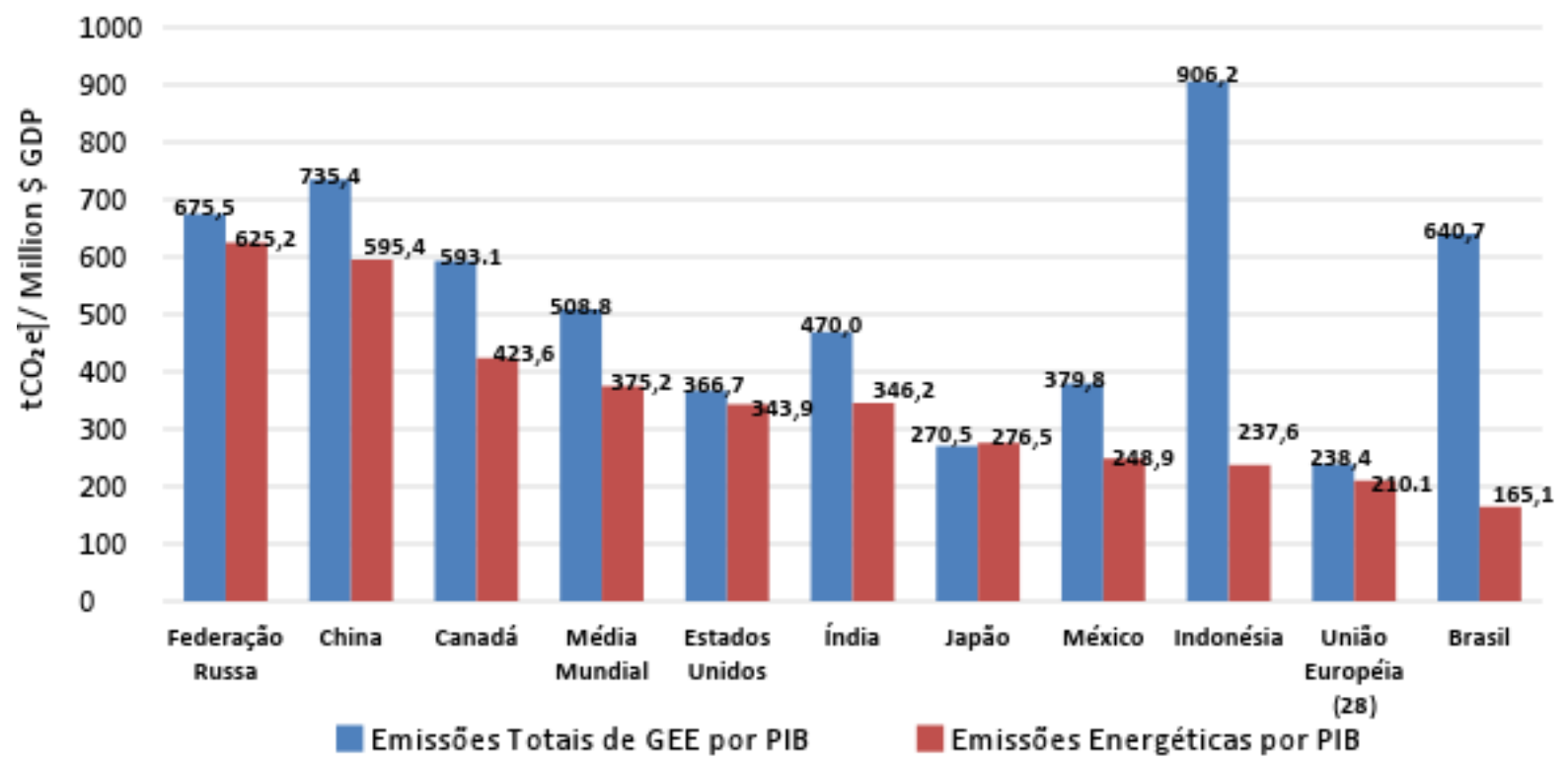

FIGURA 5 - Intensidade de emissões totais / PIB e de emissões provenientes do consumo de combustíveis fósseis para os 10 maiores emissores (2012)

FONTE: Elaboração própria a partir da base de dados da CAIT Climate Data Explorer. 2015. Washington, DC: World Resources Institute. Disponível em: http://cait.wri.org 
se observa, as intensidades variam entre os países.

Observa-se, ainda, que Indonésia, Rússia, China, Brasil e Canadá são os países que estão acima da média mundial em termos de emissões totais de GEE por PIB. Entretanto, quando se tratam das emissões provenientes do consumo de combustíveis fósseis, os dados mostram que Rússia, China e Canadá estão acima da média mundial, enquanto os 34 demais países estão abaixo da média mundial.

O que explica essas diferenças tem a ver com fatores gerais - no caso, a quantidade de emissões do país e o tamanho da economia medida pelo seu PIB -, mas, o mais relevante depende de fatores específicos, como o mix de fontes energéticas na matriz primária do país e a intensidade do uso de fontes fósseis para a geração de eletricidade e de calor, para a manufatura (indústria) e para o transporte.
Isso explica, logicamente, porque muitos países direcionam suas políticas, seus planos e iniciativas associadas, para a redução de emissões - focalizando aquelas relacionadas à oferta interna e ao consumo de energia -, enquanto que outros devem esforçar-se para reduzir as emissões associadas a outros aspectos de sua economia. Nos casos da Indonésia e do Brasil, por exemplo, cujas intensidades de emissões têm estado fortemente associadas ao desmatamento e às mudanças no uso da terra, esses devem ser, evidentemente, focos privilegiados, embora não necessariamente exclusivos, de suas políticas.

Conforme pode-se observar na Figura 6, abaixo, as emissões totais de gases de efeito estufa dos países emergentes tornaram-se relevantes a ponto de ser muito difícil nas negociações internacionais manter os chamados BRICS (Brasil,

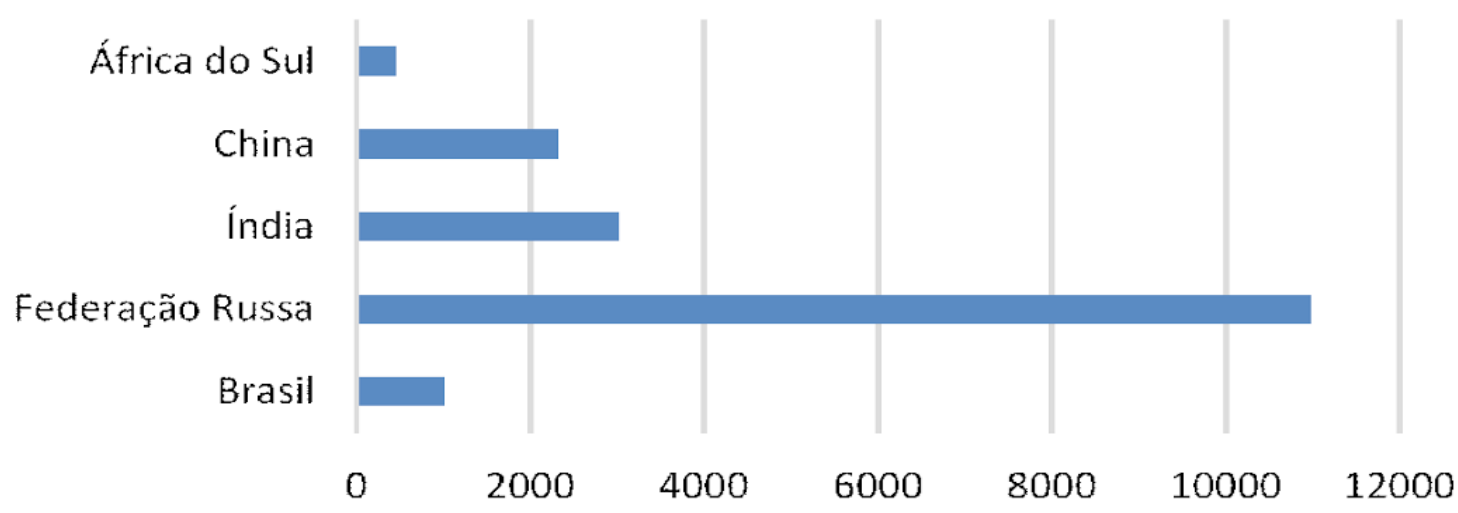

FIGURA 6 - Emissões totais de GEEs ( $\mathrm{MtCO}_{2 \mathrm{e}}$ ) excluindo AFOLU (2012)

FONTE: Elaboração própria a partir da base de dados da CAIT Climate Data Explorer. 2016. Washington, DC: World Resources Institute. Disponível em: http://cait.wri.org/historical 
Rússia, Índia, China e África do Sul) com metas puramente voluntárias num novo regime pós-Kyoto.

Esses países, que passaram por um período de crescimento acelerado - anterior à crise de 2008 -, viveram uma mudança radical no perfil de suas emissões de GEE.

Enfim, ao se considerar as mudanças trazidas pelo avanço da industrialização sobre a composição recente das contribuições dos países em desenvolvimento (ou emergentes) para as emissões correntes de GEE, concorda-se aqui que os arranjos entre os países em termos de atribuição de responsabilidades sobre as emissões acumuladas vão se tornando progressivamente defasados. Portanto, as métricas apontadas permitem reforçar a ideia de que o regime climático de Kyoto tornou-se ineficaz, além de não poder ser considerado robusto.

Ainda que se considere a importância dos estoques históricos para uma distribuição justa de responsabilidades entre os países, o vertiginoso aumento dos fluxos recentes desses gases a partir do avanço da industrialização no mundo emergente recoloca a questão da obrigatoriedade para os ajustes necessários nos países em desenvolvimento.
Encontra-se aí, portanto, uma forte evidência para as mudanças de regime climático para as negociações, conforme já observado anteriormente.

Entretanto, outras considerações são pertinentes quando se consideram outras métricas. $\mathrm{Na}$ Figura 7, abaixo, observamos as emissões totais de GEE per capita.

Esse indicador per capita permite aquilatar de outra forma as contribuições por país. Observe-se que, com essa métrica, a ordem dos dez maiores emissores se altera consideravelmente. Entre os dez principais emissores absolutos, apenas dois têm emissões per capita abaixo da média mundial, o México e a Índia. Canadá, Estados Unidos e a Federação Russa emitem mais que o dobro da média global, que é de 6,76 $\mathrm{tCO}_{2}$ e per capita. Além disso, as emissões per capita da Îndia, representam apenas um terço da média global.

Essas métricas - emissões correntes (absolutas totais e per capita) - são relevantes tanto para a compreensão dos perfis das emissões dos países/ regiões (cruciais nas negociações internacionais), quanto para deslindar elementos relevantes para identificar regiões prioritárias para a implementação

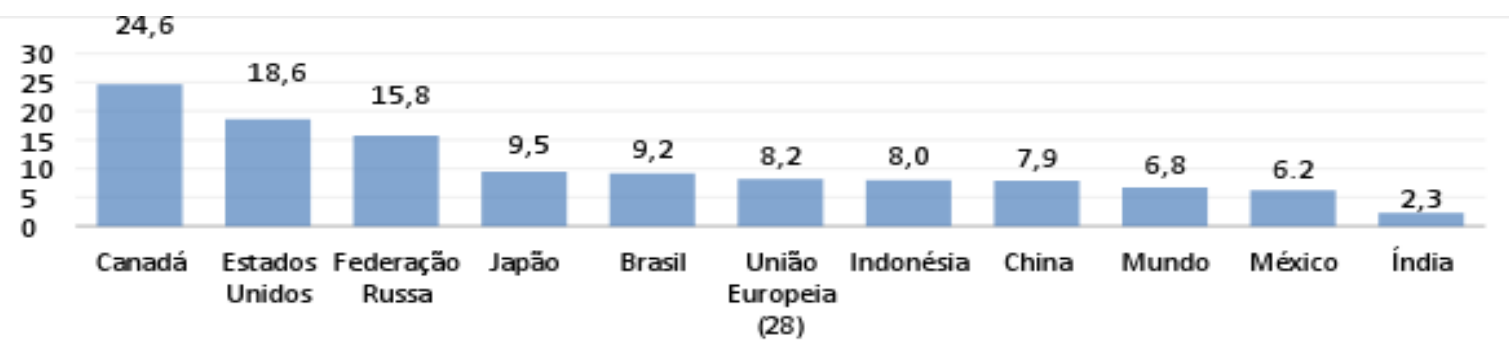

FIGURA 7 - Emissões totais per capita de GEE, incluindo AFOLU ( $\mathrm{tCO}_{2 \mathrm{e}}$ per capita), em 2012.

FONTE: Elaboração própria a partir da base de dados da CAIT - Climate Data Explorer. 2016. Washington, DC: World Resources Institute. Disponível em: http://cait.wri.org/historical

NOTA: "Mundo" corresponde às emissões médias mundiais. 
de políticas que visem a redução das emissões. Enfim, são métricas que apontam para países/ regiões que poderiam ou deveriam ser pioneiros na descarbonização de suas economias.

Além disso, deve ficar claro que um argumento que continua pertinente é o de que as emissões históricas - ou seja, as acumuladas que respondem pela maior parte da concentração desses gases na atmosfera - são resultado dos processos de desenvolvimento industrial original, concentrados, por sua vez, nos países do Anexo I no regime de Kyoto. Essas contribuições históricas continuam a explicar as concentrações atmosféricas de GEE e, por esta razão, o PRCD ainda faz sentido. As mudanças nas emissões correntes, ou seja, nos fluxos de $\mathrm{CO}_{2}$ e que vão sendo acumulados a partir do período mais recente, embora importantes e merecedoras da mais alta atenção, não mudam essa realidade a ponto de revogar a responsabilidade daquela pequena parcela da humanidade que tanto se beneficiou até então.

Todavia, essa realidade que salta aos olhos do observador não esgota as possibilidades analíticas que se abrem ao se examinar os indicadores apresentados na Tabela 2, do início da segunda seção deste artigo. Observem-se, por exemplo, os dados relativos, ainda, às emissões correntes, à população e ao PIB.

Quanto às emissões correntes, embora as contribuições dos BRICS tenham sido expressivas, se recolocarmos a Federação Russa no grupo dos poluidores mais antigos, beneficiários históricos da queima dos combustíveis fósseis, temos que as emissões correntes dos países do Anexo I (44,82\%) ainda superam - de forma significativa - a dos países, digamos, BASIC (36,19\%). Essa queima tem favorecido uma parcela relativamente pequena da população mundial (os números correntes indicam pouco mais de $18 \%$ ), contra os $40,5 \%$ da população mundial correspondente aos BASIC (novamente, sem levar em conta os problemas distributivos internos aos países). O PIB de 2012, como se pode notar, ainda ficou concentrado fortemente nos países do Anexo 1, que detiveram $63,25 \%$ do montante global, enquanto que os BASIC detiveram apenas $17,66 \%$ do total.

A maior importância relativa das emissões correntes para os países do BRICS e do BASIC precisa ser avaliada levando em conta as tendências mais recentes da divisão internacional do trabalho, com o estabelecimento de plantas industriais nesses países, que recebem investimentos de multinacionais provenientes dos países centrais, com o desenvolvimento - de forma muito desigual entre esses países - de etapas de manufatura dentro das chamadas cadeias produtivas globais. Como se sabe, as estratégias locacionais dessas empresas envolvem a busca por fatores como a mão de obra qualificada ou, por vezes, simplesmente mais barata, a disponibilidade de recursos energéticos e fontes de matéria-prima, além do acesso a mercados locais. Também são atraídas por aspectos regulatórios e de policy, como incentivos fiscais, baixa regulamentação ambiental e do trabalho, oferecimento de infraestrutura e outros benefícios pelos governos locais, dentre outros (Feenstra, 1998).

Algo análogo poderia ser dito com relação aos determinantes locacionais de empreendimentos intensivos em emissões de GEE. A este respeito, tem sido produzida uma literatura dedicada ao que se convencionou chamar "vazamento de carbono" carbon leakage. De acordo com Eichner \& Pethig (2011, p. 767): 
"Qualquer política nacional para reduzir emissões arrisca a aumentar os custos domésticos da energia e então propicia a expansão das firmas em países que não se engajam em tais políticas. Por esta razão, os esforços dos primeiros países serão compensados em alguma medida pelo crescimento das emissões nos países lenientes".

Isso implica a necessidade de políticas domésticas em todos os países para a redução das emissões. Num contexto em que apenas alguns países adotem políticas para esse fim, aqueles que não o fizerem poderão se tornar "paraísos" para investimentos em setores intensivos nessas emissões. Em tal contexto, pelo menos parte das emissões produzidas nos territórios que recebem esses investimentos não estão associadas a bens que serão consumidos nesse próprio território, mas sim nos países importadores dessa produção.

Outra implicação deste problema está relacionada com o que Boucher et al. (2016) identificam como papéis de "stakeholders non parties", com atenção especial ao setor privado. Young (2011) coloca a questão dos arranjos que envolvem a governança privada e sistemas híbridos envolvendo atores públicos e privados como um dos temas críticos para a efetividade dos regimes ambientais internacionais.

\section{Observações finais}

A discussão e a análise propostas por este artigo oferecem elementos para a compreensão dos rumos das negociações climáticas internacionais que têm levado a uma reconfiguração da arquitetura do regime climático, com mudanças substantivas em termos de liderança, de coalizão de países e de atribuição de responsabilidades.

A arquitetura do Protocolo de Kyoto colocava os países de industrialização primitiva e aqueles que se industrializaram fortemente, no período anterior ao ano de 1990, no chamado Anexo I - com responsabilidades obrigatórias para o enfrentamento das mudanças climáticas, tanto do ponto de vista do aporte de soluções tecnológicas, de recursos e do pioneirismo nas políticas públicas, sobretudo as climáticas e as energéticas. O regime climático de Kyoto abraçou os princípios de boa governança ambiental e social, como o princípio do poluidor-pagador, o da precaução, o PRCD e o princípio das responsabilidades históricas. $\mathrm{Na}$ "ausência" norte-americana devida a não-ratificação do Protocolo nos períodos dos governos Bush, a liderança foi exercida pela União Europeia. Esta e outras ausências tendem a explicar, como foi visto, a ineficácia, a falta de robustez e a instabilidade do regime climático de Kyoto.

Na nova arquitetura, que emerge a partir da COP 15, de Copenhague, novas coalizões de interesses ganharam espaço e protagonismo. Sobretudo, representadas pela vontade de participação do governo de Barack Obama - e que parece se ofuscar sob o governo Trump - e pelo BASIC.

Observou-se, neste artigo, que essa reconfiguração encontra justificativa em mudanças nos perfis de emissões de países e de grupos de países. Por outro lado, os novos interesses em coalizão parecem colocar em questão alguns dos princípios fundamentais da Convenção da ONU sobre Mudanças Climáticas.

Por fim, discute-se que essa reconfiguração não deve ser considerada ela própria livre de conflitos. A distinção entre fluxos e estoques continua sendo fundamental, uma vez que o limite de aquecimento 
de no máximo $2^{\circ} \mathrm{C}$ até o final do século XXI, que foi adotado como meta global - sobre a qual devem se dar os acordos internacionais para a limitação global das emissões -, implica que exista um máximo de concentração de emissões na atmosfera, um estoque máximo. Esse máximo de concentração implica, por sua vez, limites às emissões, ou seja, fluxos máximos. Sendo esses fluxos uma categoria global, deve haver uma partilha entre os países, ou seja: uma limitação dos fluxos de emissões de cada país a fim de compor os fluxos totais e, daí suas contribuições específicas para o estoque máximo.

O conflito deve ficar mais claro quando se considera a questão distributiva com relação ao clima: um acesso equitativo ao Orçamento Global de Carbono (Global Carbon Budget) - um global common-significaria limitar as emissões per capita a cerca de 1 a 3 toneladas por habitante ao ano no horizonte de 2050 para que o planeta aquecesse "apenas $2^{\circ} \mathrm{C}$ " até o final do século. Assim como PIB per capita é um valor médio, que nada tem a ver com distribuição, o orçamento global de carbono deve ser distribuído entre as nações. Este também é um aspecto fundamental para se compreender as dificuldades das negociações internacionais sobre mudanças climáticas que estão em curso e as que estão por vir.

Observa-se que despontam avaliações que consideram a natureza voluntária das NDCs, as quais podem ser apreciadas nos trabalhos de Bueno Rubial, 2016; Carraro, 2016; Afionis, 2017; Heal \& Kunreuther, 2017; como elemento que confere um caráter bottom up ao novo regime. É possível, ainda, notar que a percepção de Bodansky (2016) de que não é perfeitamente possível avaliar o Acordo de Paris como legalmente vinculante, o que contribui para que se questione uma hierarquia top down.
Ademais, é preciso advertir que um caráter bottom up não constitui uma característica que contribua para a efetividade do novo regime. Esta ainda é uma questão em aberto.

Para direções de futuras investigações, duas questões se colocam, a partir do estudo que aqui se apresentou. De um lado, a necessidade de investigar a adequação e a efetividade das NDCs para que as metas estabelecidas no Acordo de Paris sejam cumpridas. De outro, a necessidade de se incluir, dentro do arcabouço analítico dos regimes climáticos, a questão do setor privado tanto no que diz respeito a se levar em conta o cômputo de suas emissões de GEE no âmbito do desenho desses regimes, quanto na inclusão de suas contribuições para efeito de uma discussão ampliada do Princípio das Responsabilidades.

\section{Agradecimentos}

Agradecemos ao $\mathrm{CNPq}$ pelo financiamento na forma de bolsa de mestrado, a Capes pelo financiamento na forma de bolsa de doutorado e aos Professores Doutores André Tosi Furtado (DPCT-IG/Unicamp) e Carla Kazue Nakao Cavaliero (FEM/Unicamp) por contribuições e comentários à primeira versão deste artigo. Apresentamos nosso reconhecimento ao Editor, aos dois pareceristas anônimos indicados pela Revista DMA e pelo revisor, pela minuciosa leitura, pela criteriosa avaliação e, não menos importante, pelas valiosas recomendações feitas à versão inicial do artigo. Eventuais erros e imprecisões restam, como de praxe, da inteira responsabilidade das autoras. 
* Este artigo trata-se de desenvolvimentos conceituais, empíricos e analíticos vinculados a tese de doutorado de Maria Cristina Oliveira Souza, do programa de pós-graduação em Política Científica e Tecnológia (PPG-PCT) do Instituto de Geociências da Universidade Estadual de Campinas. As autoras expressam reconhecimento à Capes pelo apoio ao projeto na forma de bolsa de doutorado (Processo no 1733714)".

\section{Referências}

Afionis, S. The European Union in International Climate Change Negotiations. Taylor \& Francis, 2017.

Amorim, A.; Santos, M.; Esteves, P. Resultados da COP 21 e a participação do BASIC BPC Policy Brief. 2016. Disponível em: http://bricspolicycenter.org/homolog/uploads/ trabalhos/7117/doc/27956004.pdf. Acesso em: mar. 2017.

Bernauer, T. Climate change politics. Annual Review of Political Science, 16, 421-448, 2013. doi: 10.1146/annurev-polisci-062011-154926

Bodansky, D. The legal character of the Paris Agreement. Review of European, Comparative \& International Environmental Law, (25)2, 142-150, 2016. doi: 10.2139/ ssrn. 2735252

Boucher, O.; Bellassenb, V.; Benvenistec, H.; Ciaisd, P; Criquie, P.; Guivarchf, C.; Le Treutc, H.; Mathye, S.; Séfériang, R. Opinion: In the wake of Paris Agreement, scientists must embrace new directions for climate change research. Proceedings of the National Academy of Sciences, (113)27, 7287-7290, 2016. doi: 10.1073/pnas.1607739113

Bueno Rubial, M. d. P. El Acuerdo de París: ¿una nueva idea sobre la arquitectura climática internacional?. Relaciones Internacionales, 33, 75-95. 2016. Disponível em: $<\mathrm{http}$ ://www.relacionesinternacionales.info/ojs/index.php?journal=Relaciones_Internacionales\&page $=$ article\&op $=$ view\&path $\% 5 \mathrm{~B} \% 5 \overline{\mathrm{D}}=747>$

Carraro, C. A Bottom-Up, Non-Cooperative Approach to
Climate Change Control: Assessment and Comparison of Nationally Determined Contributions (NDCs). Journal of Sustainable Development, (9)5, 175-186, 2016. doi: 10.5539/jsd.v9n5p175

Corazza, R. I.; Bonacelli, M. B. M. Ciência, Tecnologia e Inovação para a Sustentabilidade: reflexões em [retro] [per]spectiva. In: Monteiro, M.; Dias, R. de B.; Campos, C. de (Orgs.) Novos Horizontes em Politica Cientifica e Tecnológica, São Paulo: Ed. UFABC, 2014.

Dimitrov, R. S. The Paris agreement on climate change: Behind closed doors. Global Environmental Politics, 2016. doi: 10.1162/GLEP_a_00361

Eichner, T.; Pethig, R. Carbon leakage, the green paradox, and perfect future markets. International Economic Review, 52(3), 767-805. 2011. doi: 10.1111/j. 1468-2354.2011.00649.x

Feenstra, R. C. Integration of trade and disintegration of production in the global economy. The Journal of Economic Perspectives, 12(4), 31-50. 1998. doi: 10.1257/jep.12.4.3

Feeny, D.; Berkes, F.; McCay, B. J.; Acheson J. M. The tragedy of the commons: twenty-two years later. Human Ecology, (18) 1, 1-19, 1990.

Ferreira, L. Em decisão histórica, EUA e China comprometem-se a cortar gases estufa em pacto global. 2011. Disponível em: <http://noticias.uol.com.br/ciencia/ultimas-noticias/ redacao/2011/12/11/em-decisao-historica-eua-e-china-comprometem-se-a-cortar-gases-estufa-em-pacto-global.htm>. Acesso em: abr. 2016.

Gupta, J. Negotiating challenges and climate change. Climate Policy, (12)5, p. 630-644, 2012. doi: 10.1080/14693062.2012.693392

Haggard, S.; Simmons, B. A. Theories of international regimes. International Organization, (41)3, 491-517, 1987. doi: $10.1017 / \mathrm{S} 0020818300027569$

Heal, G.; Kunreuther, H. An alternative framework for negotiating climate policies. Climatic Change, 1-11, 2017. doi: 10.1007/s10584-017-2043-8

IPCC - Intergovernmental Panel in Climate Change. Mudança do Clima 2007: A Base das Ciências Físicas. Contribuição do Grupo de Trabalho I ao Quarto Relatório 
de Avaliação do Painel Intergovernamental sobre Mudança do Clima. 2007a. Disponível em: $<$ https://www.ipcc.ch/pdf/ reports-nonUN-translations/portuguese/ar4-wg1-spm.pdf $>$ Acesso em: jun. 2016.

IPCC - Intergovernmental Panel in Climate Change. Mudança do Clima 2007: Impactos, Adaptação e Vulnerabilidade. Contribuição do Grupo de Trabalho II ao Quarto Relatório de Avaliação do Painel Intergovernamental sobre Mudança do Clima. 2007b. Disponível em: $<$ https://www. ipcc.ch/pdf/reports-nonUN-translations/portuguese/ar4-wg2-spm.pdf> Acesso em: jun. 2016.

IPCC - Intergovernmental Panel in Climate Change. Climate Change 2014: Mitigation of Climate Change. Contribution of Working Group III to the Fifth Assessment Report of the Intergovernmental Panel on Climate Change. Edenhofer, O.;Pichs-Madruga, R.; Sokona,Y.; Farahani, E.; Kadner, S.; Seyboth, K.; Adler, A.; Baum, I.; Brunner,S.; Eickemeier,P.; Kriemann, B.; Savolainen, J.; Schlömer, S.; Stechow, C. von.; Zwickel, T.; Minx, J. C. (Eds.). Cambridge/New York, Cambridge University Press/IPCC, 2014a. Disponível em: $<$ http://www.ipcc.ch/pdf/assessment-report/ ar5/wg3/ipcc_wg3_ar5_full.pdf $>$. Acesso em: ago. 2016.

Kaul, I.; Grunberg, I.; Stern, M. (Ed.). Global Public Goods: International Cooperation in the 21st Century. New York: Oxford University Press, 1999. Oxford Scholarship Online, 2003. doi: 10.1093/0195130529.001.0001

Keohane, R. O. The demand for international regimes. International organization, (36)2, 325-355, 1982.

Krasner, S. D. Causas estruturais e consequências dos regimes internacionais. Revista de Sociologia e Política, (20)42, 93, 2012. doi: 10.1590/S0104-44782012000200008

Nações Unidas. Adoção do Acordo de Paris. 2015. Disponível em: $<$ https://nacoesunidas.org/wp-content/uploads/2016/04/Acordo-de-Paris.pdf $>$. Acesso em: nov. 2015.

Okereke, C.; Coventry, P.; Climate justice and the international regime: before, during, and after Paris. WIREs Clim Change, 7, 834-851, 2016. doi: 10.1002/wcc.419

Ostrom, E.; Burger, J.; Field, C. B.; Norgaard, R. B.; Policansky, D. Revisiting the commons: local lessons, global challenges. Science, 284(5412), 278-282. 1999. doi: science. 284.5412 .278
Ribeiro, W. C. Mudanças climáticas, realismo e multilateralismo. Terra Livre, 18(1), 75-84, 2002. Disponível em: http://www.agb.org.br/publicacoes/index.php/terralivre/ article/view/144/135

Rockström,J.; Steffen, W.; Noone, K.; Persson, Å.; Chapin III, F. S.; Lambin, E. F.; Lenton,T. M., Scheffer, M.; Folke, C.; Schellnhuber, H.J.; Nykvist, B.; Wit, C. A. de.; Hughes, T.; Leeuw, S. van. der.; Rodhe, H.; Sörlin,S.; Snyder, P. K.; Costanza, R.; Svedin,U.; Falkenmark, M.; Karlberg, L.; Corell, R. W.; Fabry, V. J; Hansen, J.; Walker, B.; Liverman, D.; Richardson, K.; Crutzen, P.; Foley, J. A. A safe operating space for humanity. Nature, [s.1.], (461)7263, 472-475, 24 set. 2009. doi: 10.1038/461472a

Sampaio, J. A. L.; Wold, C.; Nardy, A. Princípios de Direito Ambiental. Belo Horizonte: del Rey, 304 p, 2003.

Schmeller, J. Especialistas avaliam saída do Canadá do Protocolo de Kyoto. 2011. Disponível em: <http://www. dw.com/pt-br/especialistas-avaliam-saída-do-canadá-do-protocolo-de-kyoto/a-15599653>. Acesso em: abr. 2016.

Steffen, W.; Richardson, K.; Rockström, J.; Cornell, S. E.; Fetzer, I.; Bennett, E. M.; Biggs, R.; Carpenter, S. R.; Vries, W. de.; Wit, C. A. de.; Folke, C.; Gerten, D.; Heinke, J.; Mace, G. M.; Persson, L. M.; Ramanathan, V.; Reyers, B.; Sörlin, S. Planetary boundaries: Guiding human development on a changing planet. Science, (347)6223, 1259855, 2015. doi: 10.1126/science. 1259855

Stern, N. The Economics of Climate Change: The Stern Review. 6. ed. United Kingdom: Cambridge, 692 p, 2009.

Strange, S. Cave! hic dragones: a critique of regime analysis. International Organization, (36)2, 479-496, 1982.

UNITED NATIONS - FRAMEWORK CONVENTION ON CLIMATE CHANGE (UNFCCC). The Paris Agreement.2016. $<$ http://unfccc.int/paris_agreement/items/9485. php>. Acesso em: mar. 2016

Viola, E. O regime internacional de mudança climática e o Brasil. Revista Brasileira de Ciências Sociais, (17)50, 2546, 2002. doi: 10.1590/S0102-69092002000300003

Viola, E. Brasil na arena internacional de mitigação da mudança climática. Rio de Janeiro: Cindes, 2009. Disponível em: <http://www.ipea.gov.br/bric/textos/100409_BRICVio- 
la1.pdf>. Acesso em: dez. 2016.

Viola, E. A dinâmica das potências climáticas e o Acordo de Copenhague. Boletim da Sociedade Brasileira de Economia Ecológica. Edição Especial, 23-24,16-22, 2010. Disponível em: $<$ http://www.ecoeco.org.br/conteudo/publicacoes/boletim_ecoeco/Boletim_Ecoeco_n023_24.pdf>

Viola, E.; Basso, L. Wandering decarbonization: the BRIC countries as conservative climate powers. Revista Brasileira de Politica Internacional, 59(1), e001, 2016. doi: 10.1590/0034-7329201600101
Young, O. R. Regime dynamics: the rise and fall of international regimes. International Organization, (36)2, 277-297, 1982.

Young, O. R. Effectiveness of international environmental regimes: Existing knowledge, cutting-edge themes, and research strategies. Proceedings of the National Academy of Sciences, (108)50, 19853-19860, 2011. doi: 10.1073/ pnas. 1111690108 